\title{
REACTOR/SEPARATOR PROCESSES WITH RECYCLE-1. CANDIDATE CONTROL STRUCTURE FOR OPERABILITY
}

\author{
KWo-LIang; Wu and CHIING-CHING; Yut \\ Department of Chemical Enginecring. National Taiwan Institute of Technology, Taipei, Taiwan I06. \\ ROC
}

(Received 3 January 1995; final revision received II September 1995)

\begin{abstract}
The economic and environmental considerations often lead to more stringent process design In terms of plant operation. this means the existence of recycle structures in processing plants. The steady-state and dynamic hehaviors of the reactor/separator system differ significantly from their individual unit counterparts. A notable difference is the limited throughput handling capability when the control structure (selection of controlied and manipulated variables) is not appropriately chosen. Since the extra work, resulting from load change, is not evenly distributed among process units, this imbalance leads to large deviations in some process variables. Analyses are given to illustrate this effect and a control structure is proposed to overcome this disturbance rejection problem. Furthermore, a systematic tuning procedure is also proposed to find the controller parameters in plantwide control. A reactor/ separator process is used to illustrate effectiveness of the balanced control structure and controller tuning procedure. Simulation results show that the balanced scheme can handle large load changes while maintaining good dynamic performance.

Copyright (C) 1996 Elsevier Science Ltd
\end{abstract}

\section{INTROIJUCTION}

Typical chemical processes consist of many process subunits. Therefore, the success of the production depends a great deal on the smooth operation of all these subunits. A significant research effort has been dedicated to the design and control of individual process unit, e.g., reactor (Perlmutter, 1965: Lee and Weekman, 1976; Ray, 1983) or distillation column (Shinskey, 1984; Buckley et al., 1985; Luyben, 1992). However, as the results of stringent environmental regulation and economic consideration, today's chemical plants tend to be highly integrated and interconnected. Moreover, the steady-state and dynamic behaviors of these interconnected units differ significantly from individual subunits. Therefore, the problem of plantwide control becomes the operation and control of these interconnected process units. Typical interconnected process units is the recycle system: process with material recycle.

Conventional wisdom to handle plants with recycle streams is to install large surge tanks between process units. This alleviates the dynamic interaction from material recycle. However, this practice can be economically expensive and environmentally unacceptable, especially when hazardous chemicals are involved. Therefore, modern chemical processes

$\uparrow$ Author to whom all correspondence should be addressed. have to face the problem of steady-state and dynamic interactions arised from today's process design requirement.

Dynamics and control of processes with recycle streams received little attention until recently. A pioneering work of Gilliland et al. (1964) studies the dynamics of a reactor/separator system. They point out that the effect of the recylce stream increases the time constants of the process. Verykios and Luyben (1978) studied a slightly more complex process with simplified column dynamics and they show that these recycle systems can exhibit underdamped behavior. Denn and Lavie (1982) also show that the response time of recycle systems can be substantially longer than the response time of individual unit. Papadourakis et al. (1987) show that the relative gain array (RGA; Bristol, 1966) of individual unit does not give a correct measure of the steady-state interactions in a recycle system. Taiwo (1986) discusses robust control of plants with recycle. In a series of papers, Luyben and coworker (Luyben. 1993a-c, 1994; Tyreus and Luyben, 1993) invstigate the effects of recycle loop on process dynamics and the interaction between design and control is also studied for several process systems with different level of complexity, e.g., different number of process units and chemical species. Downs and Vogel (1993), based on a commercial process system, propose a benchmark plantwide control problem, the Tennessee Eastman problem, for the purpose of developing, studying and evaluating process control 


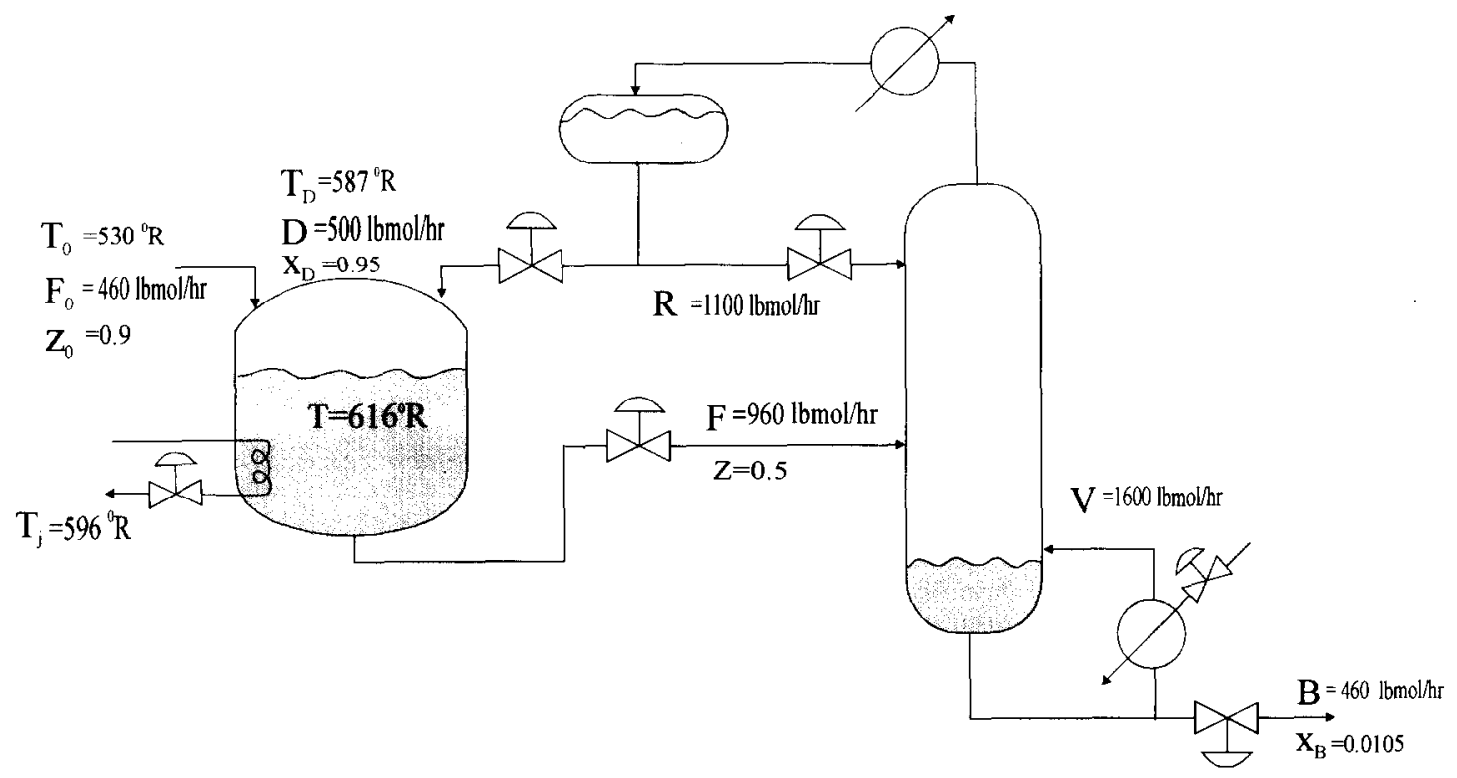

Fig. 1. Reactor/separator process with recycle

technology. McAvoy and Ye (1993) propose a base control strategy for the Tennessee Eastman control problem. Price and Georgakis (1993) describe a procedure that is based on a tiered framework for plantwide control system design and the procedure is justified through an extensive set of dynamic simulations based on the IAE (integrated absolute error) criterion and the methodology is applied to the Tennessee Eastman problem (Price et al., 1994). Luyben and Floudas (1994) present a systematic procedure to analyse the interaction between design and control at the process synthesis stage. The process synthesis is formulated as an optimization problem by taking both steady-state economic and open-loop controllability into account.

The primary objective of process control system is to maintain smooth operation in the face of disturbances. That means the process should remain operable; when the throughput, purity of raw material and product specifications change. However, as indicated by Luyben (1994), for some control configurations, the recycle system may exhibit a snowball effect as the feed condition changes. For example, a small change is the fresh feed flow rate could lead to a significant increase in the recycle stream. This is a unique feature of recycle systems. The purpose of this work is to study the cause of this snowball effect. Furthermore, a control structure is proposed for disturbance rejection in plantwide control and a systematic controller tuning procedure is also proposed. This paper is organized as follows. The recycle system is studied and process characteristics for the individual units and the interconnected system are also given in Section 2. Physical insights for the snowball effect are given by analysing steadystate behavior under load changes and a control structure is also proposed in Section 3. Section 4 discusses the controllability and operability of different control structures. A tuning procedure is presented for plantwide control and dynamic performance is also compared for different control structures in Section 5. Conclusions are drawn in Section 6.

\section{RECYCLE SYSTEMS}

A different prospective is offered to give physical insight into recycle systems. The way an individual process unit handling load disturbances is investigated first and a similar concept for disturbance rejection is extended to interconnceted units. Consequently, a control structure is devised from the operability (how the system handling load disturbance) point of view.

\subsection{Process}

Before looking into process characteristics, a simple reactor/separator process is described. The process studied is a flowsheet consists of a reactor and a distillation column in an interconnected structure as shown in Fig. 1 (Papadourakis et al., 1987). An irreversible first order reaction $(\mathbb{A} \rightarrow \mathbb{B})$ occurs in a continuous stirred tank reactor (CSTR). The reaction rate $(k)$ is a function of temperature described by Arrhenius expression. This is an exothermic reaction and the reactor temperature $(T)$ is controlled by manipulating cooling water flow rate. Some of the reactant $A$ is consumed in the CSTR 
and the effluent of the reactor, a mixture of $A$ and $\mathbb{B}$, is fed into a 20 -tray distillation column. The product $\mathbb{B}$ is recycled back into the CSTR. The column has a partial reboiler and a total condenser. Constant relative volatility $(\alpha=2.0)$ is assumed for the modeling purpose. Table 1 gives the nominal operating condition for the process.

The steady-state equations play an important role in analysing this recycle system. From material balances, we have (Luyben, 1994):

$$
\begin{array}{ll}
\text { reactor: } & F_{10}+D=F \\
& F_{10} z_{11}+D x_{10}=F z+V_{\mathrm{R}} k z \\
\text { column: } & F=D+B \\
& F z=D x_{10}+B x_{13} \\
\text { overall: } & F_{10}=B
\end{array}
$$

Note that the external flows into and out of the system are the reactor fresh feed flow rate $\left(F_{11}\right)$ and the column bottoms flow rate $(B)$. respectively.

Rearranging equations (2), (4) and (5), we have:

$$
F_{11}\left(z_{11}-x_{\mathrm{B}}\right)=V_{\mathrm{R}} k z
$$

and rearranging equations (3)-(5), we have:

$$
\frac{F}{F_{0}}=\left(\frac{x_{13}-x_{13}}{x_{13}-z}\right) \text {. }
$$

Equation (6) and (7) give some insight into this reactor/separation system. For example, three possible process variables to handle external load changes, i.e., changes in $F_{11}$ or $z_{11}$ arc ractor holdup $\left(V_{R}\right)$, reaction rate constant $(k)$ and reactor composition (mole fraction of light component $A_{j}$ ) $z$. Conventionally, $V_{\mathrm{R}}$ (via level control) and $k$ (via reactor temperature control) are kept constant and this, subsequently, results in significant change in the reactor composition $z$. Once significant deviation occurs in $z$, this results in large changes in the internal flows (e.g., $F$ as shown in equation 7 ). Therefore, the disturbance rejection capabilitics of different control structures can be analysed from these steady-state equations (equation 1-7). The experience from disturbance rejection capability of individual unit can be useful for recycle systems.

\subsection{Process characteristics-individual unit}

2.2.1. Separator. Consider a simple distillation column with one feed and two product streams (Fig. 2). Assuming that the top and bottoms compositions $\left(x_{1}\right.$ ) and $x_{\mathrm{B}}$ ) are controlled (e.g., by manipulating $R$ and $V, D$ and $V$ or $D$ and $B$ ). Typical load disturbances are feed flow rate $(F)$ changes and feed composition $(z)$ changes. Let us consider the case of feed flow rate change. In order to maintain product specifications, all flow rates (i.e., $R, D, V$ and $B$ ) have to grow in proportion to the factor of change in

\begin{tabular}{|c|c|c|}
\hline \multicolumn{3}{|l|}{ CSTR } \\
\hline fresh feed flow ratc $\left(F_{i}\right)$ & $4(x) .(x)$ & $(\mathrm{lh} \mathrm{mol} / \mathrm{hr})$ \\
\hline fresh feed composition $\left(z_{11}\right)$ & $0.900(0) 00$ & (mole fraction) \\
\hline lresh feed temperatture $\left(l_{n}\right)$ & $530.0(k)$ & $\left({ }^{\prime} R\right)$ \\
\hline recycle llow rate $(l)$ & $5(x) .(x)(x)$ & (llo mol/hr) \\
\hline recycle stream compesition $\left(x_{1}\right)$ & 0.95 & (mole fraction) \\
\hline recvele stream temperature $\left(T_{1}\right)$ & $5 \times 7.156$ & $\left({ }^{\circ} \mathrm{R}\right)$ \\
\hline reactor lemperature $(T)$ & 616.425 & $\left({ }^{\circ} \mathbf{R}\right)$ \\
\hline jacket temperature $\left(T_{\mathrm{i}}\right)$ & 596.07 & $\left({ }^{\circ} \mathrm{R}\right)$ \\
\hline reactor holdup $\left(V_{R}\right)$ & $24(x) .945$ & (lb mol) \\
\hline activation encrgy $(l)$ & $30 \times 41.770$ & (Btw/lb mol) \\
\hline pre-exponsential fictor $\left(k_{11}\right)$ & $2.8297 .10^{111}$ & $\left(h r^{1}\right)$ \\
\hline reactor residence time & 2.5 & (hr) \\
\hline overall heal-transfer coeflicient $(U)$ & 1.501 .51851 & $\left(\mathrm{Btu} / \mathrm{hrt1}{ }^{\circ} \mathrm{R}\right)$ \\
\hline heat capacity $\left(C_{p}\right)$ & 0.75 & $\left(\mathrm{Btu} / \mathrm{ll},{ }_{, .}{ }^{\circ} \mathrm{R}\right)$ \\
\hline heat of raction $(\lambda)$ & $-30(x)(10.100)$ & (Btu/lb mol) \\
\hline \multicolumn{3}{|l|}{ Distillation } \\
\hline column ficed flow ratc $(l)$ & 460.378 & (lh mol/hr) \\
\hline column lecal composition $(z)$ & $0.5(0)(0) 0$ & (mole lraction) \\
\hline rellux flow rate $(R)$ & 11010.045 & (li) $\mathrm{mol} / \mathrm{hr}$ ) \\
\hline distillatc llow rate $(D)$ & 500.378 & (lh mol/hr) \\
\hline rellux ritio $(R R)$ & 2.19842 & (mole fraction) \\
\hline bottoms flow ratc $(B)$ & $46(0.100)$ & (lh $\mathrm{mol} / \mathrm{hr}$ ) \\
\hline vapor boil-up (V) & $1(x)(0.423$ & $(1 \mathrm{~h} \mathrm{~mol} / \mathrm{hr})$ \\
\hline bottoms composition $\left(x_{13}\right)$ & 0.0101050 & (mole fraction) \\
\hline no. of trays $(N T)$ & 20 & \\
\hline leced tray $(N /)$ & 12 & \\
\hline relative volatility $(a)$ & 2 & \\
\hline liquid hydratalic time constant $(\beta)$ & $0.0(0) 11$ & $(\mathrm{hr})$ \\
\hline boltoms holdup $\left(M_{13}\right)$ & 275 & (lb mol) \\
\hline rellux drum holdup $\left(M_{12}\right)$ & 18.5 & (lb mol) \\
\hline Iray holdinp $\left(M_{n}\right)$ & 23.5 & (lh mol/tray) \\
\hline
\end{tabular}
the feed flow rate. That means a simple way to overcome throughput changes is to adjust all flow rates by the same factor. This is exactly the rcason why absolute values of flow rates are not mandatory

Table 1. Parameter values and steady-state condition for reactor/separator system 


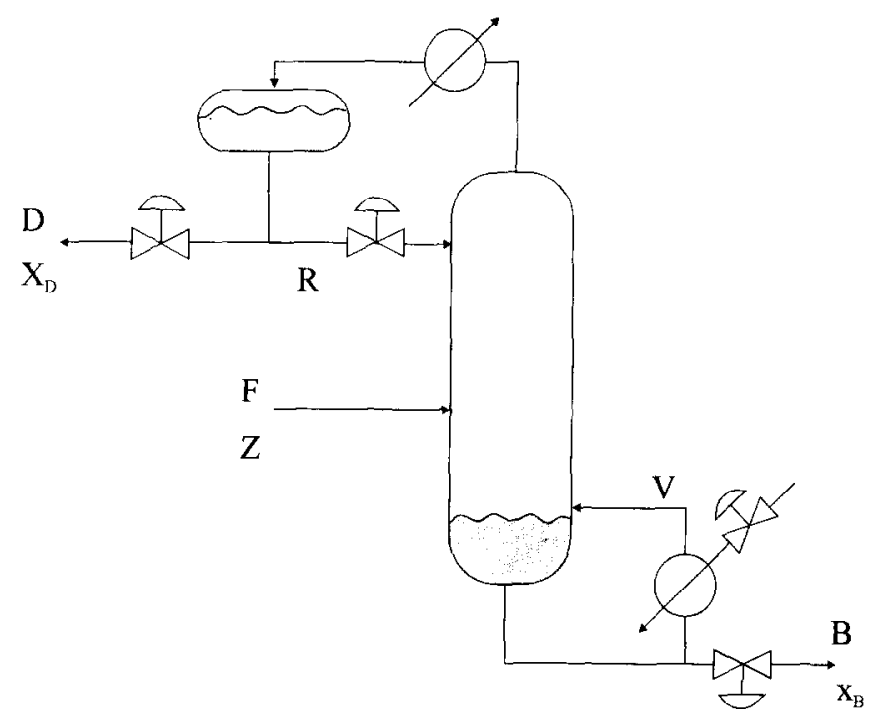

Fig. 2. Distillation column.

for steady-state column simulation. As for feed composition $(z)$ changes, all flow rates have to be adjusted in order to maintain product specifications. However, changes in these flow rates can be neither linear nor monotone as shown by Luyben (1975).

In order to quantify "work" required, minimum work $\left(W_{\min }\right)$ (Henley and Seader, 1981) for separation is employed. For a binary system, $W_{\min }$ is defined as:

$$
\begin{aligned}
-W_{\min }= & R T\left\{\left[D x_{\mathrm{D}} \ln \left(\frac{x_{\mathrm{D}}}{z}\right)+B x_{\mathrm{B}} \ln \left(\frac{x_{\mathrm{B}}}{z}\right)\right]\right. \\
& +\left[D\left(1-x_{\mathrm{D}}\right) \ln \left(\frac{1-x_{\mathrm{D}}}{1-z}\right)+B\left(1-x_{\mathrm{B}}\right)\right. \\
& \left.\left.\times \ln \left(\frac{1-x_{\mathrm{B}}}{1-z}\right)\right]\right\} .
\end{aligned}
$$

For the binary column studied (Table 1), the minimum work increases linearly (with a slope of unity) with an increase in the feed flow rate $F$, as shown in Fig. 3. For feed composition ( $z$ ) changes, $W_{\min }$ has a maximum at $z=0.5$ and decreases symmetrically for changes in $z$ (Fig. 3). Similar behavior can be observed for the changes in the vapor boil-up $V$. Despite the fact that the minimum work is an explicit measure for the work done by a distillation column, the vapor boil-up is used in the subsequent development since it is a simple measure and gives similar behavior description for the work done by a column.

2.2.2. Reactor. Consider a continuous stirred tank reactor (CSTR) in Fig. 4 with a first order reaction. Typically, the reactor temperature is controlled by manipulating cooling water flow rate.
It is clear that keeping reactor temperature constant does not mean the reactor composition $(z)$ is maintained at its set point. The reactor conversion is a good measure of the reactor performance. The reactor conversion $(\xi)$ is defined as:

$$
z=z_{11}(1-\xi) \text {. }
$$

For a CSTR with a first order reaction, $\xi$ can be expressed as:

$$
\xi=\frac{k\left(V_{\mathrm{R}} / F\right)}{1+k\left(V_{\mathrm{R}} / F\right)}
$$

where $V_{\mathrm{R}}$ is the reactor holdup and $F$ is the reactor effluent flow rate. For the case of the fresh feed flow changes $\left(F_{0}\right.$ or $\left.F\right)$, the reactor holdup has to be adjusted simultaneously in order to maintain the extent of the reaction. It is clear that residence time $\left(V_{\mathrm{R}} / F\right)$ in the reactor has to be kept constant for the same performance. Similarly, equations (9) and (10) show that $V_{R}$ has to be changed under fresh feed composition $\left(z_{0}\right)$ changes. Therefore, load changes $\left(F_{10}\right.$ or $\left.z_{10}\right)$ for reactor control can be handled by changing the reactor holdup and the magnitude of change is characterized by equations (9) and (10).

\subsection{Process characteristics-interconnected units}

The plant considered has a reactor and a separator connected under a recycle structure (Fig. 1). Since the system consists of two process units, an additional degree of freedom appears under load changes. For example, when the throughput increases, additional work, resulted from this change, should be distributed between these two units. It is interesting to see how different control 
structures make this distribution. Two control structures are studied, the conventional structure and the structure proposed by Luyben (1994: referred to as the Luyben structure hereafter). A new control structure is also proposed. These control structures are classified according to the effort done to overcome throughput changes.

\section{PLANTWIDE STRUCTURES}

For a systems with multiple subunits, alternatives exist to handle load disturbances. For example, the effect of a throughput change can mostly be absorbed by a single subunit or can be evenly handled by all subunits. Inappropriate disturbance handling can lead to unreasonable demand on the capacity of individual unit and, consequently, result in the "snowball" effect (Luyben, 1994).

\subsection{Unbalanced schemes}

Unlike individual unit, if load changes are handled mostly by a single unit in a plantwide system,
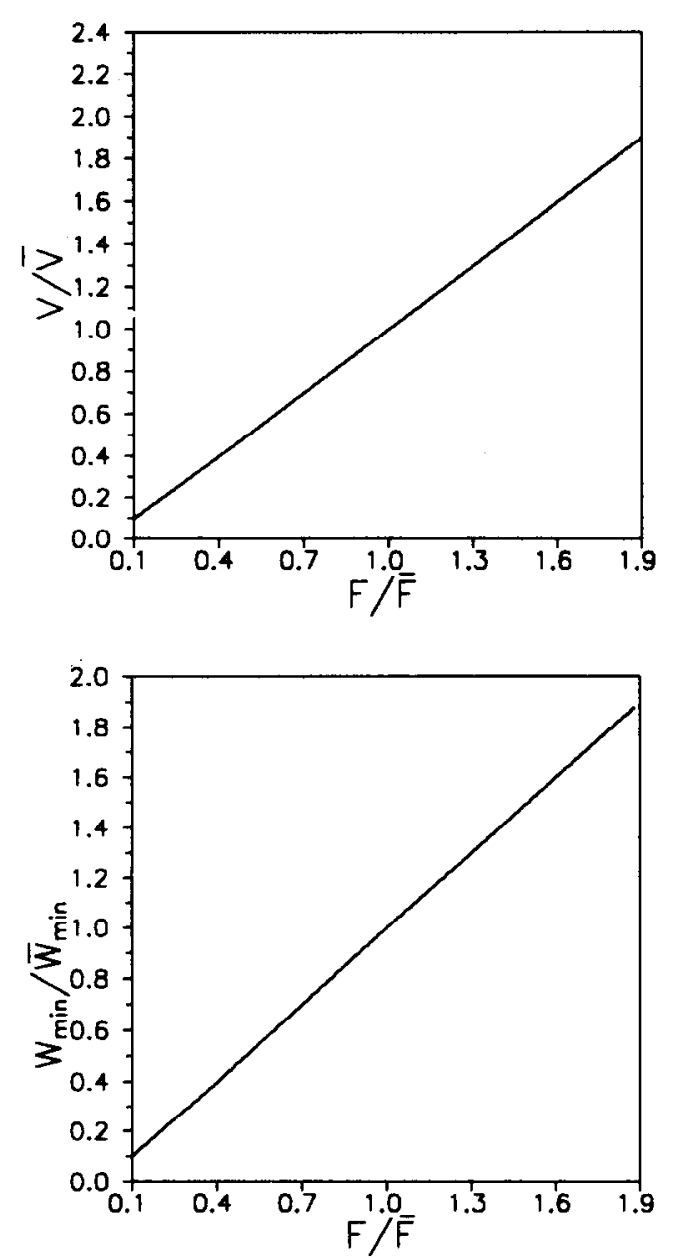

some of the process variables (e.g. , llow rates, level, etc.) can hit operational constraints for a very small load change.

3.1.1. Column Overwork. Let use first consider the conventional control structure (Fig. 5a) where the reactor holdup $\left(V_{\mathrm{R}}\right)$ is kept constant by changing the reactor effluent flow rate $(F)$. On the column side, both the top and bottoms compositions $\left(x_{\mathrm{D}}\right.$ and $x_{13}$ ) are controlled by manipulating the reflux flow rate $(R)$ and vapor boil-up $(V)$, respectively.

A distinct feature of this structure is that the reactor holdup is kept constant (Fig. 5a). This practice gives little problem for plants that connected as cascade units. However, for recycle systems, the practice of constant reactor holdup may require the separator to work much harder to maintain product specifications. Consider the case of a throughput $\left(F_{11}\right)$ increase. For an individual reactor, the reactor holdup has to increase proportionally in order to keep the expected performance (equations 9 and 10). In this conventional structure, since the reactor level is kept constant, the reactor composition $(z)$
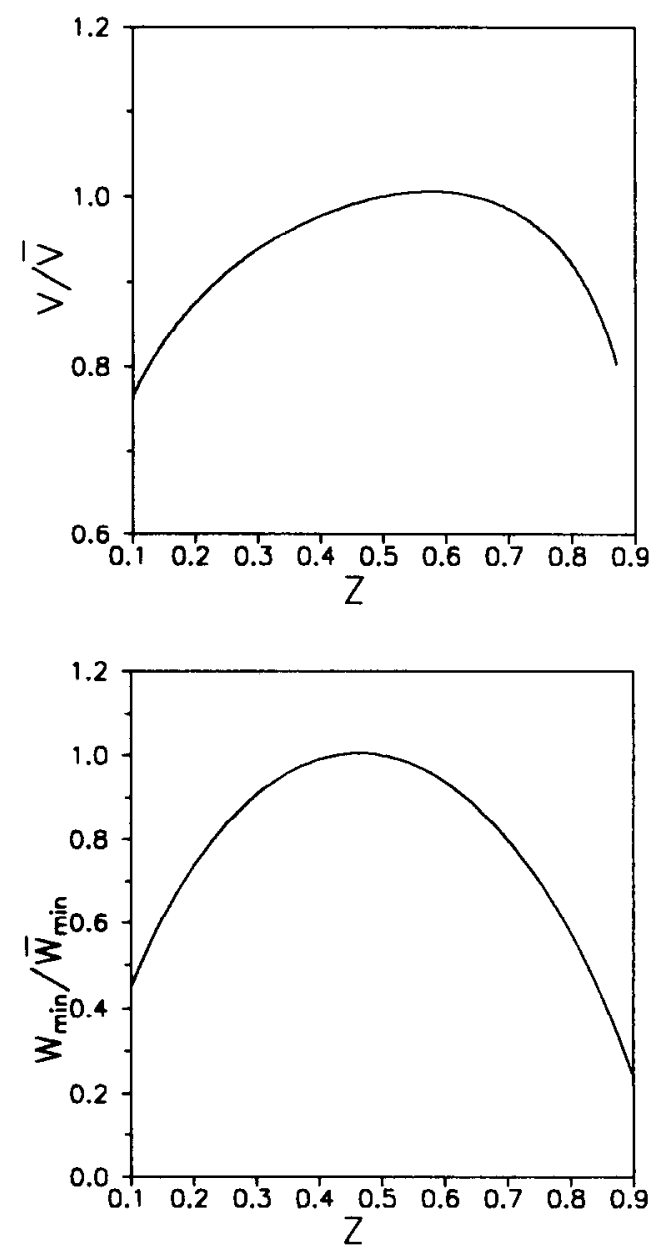

Fig. 3. Minimum work for separation and vapor boilup for distillation column under feed flow $(F)$ and leed composition $(z)$ changes. 


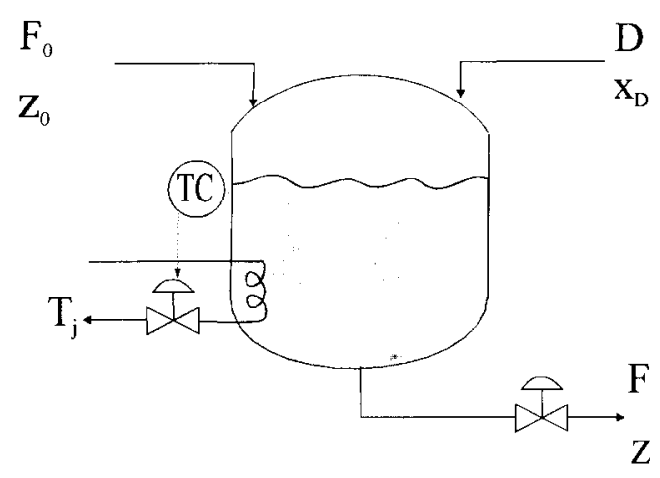

Fig. 4. Reactor.

(or the column feed composition) remains high (as the result of a smaller residence time) along with an increased feed flow rate $(F)$ (Fig. 6). The increases in both the feed flow rate $(F)$ and feed composition (z) make the column boils much more light component up to the top and, subsequently, recycles back to the reactor in order to maintain the product specification. Actually, the resultant process variables can be derived analytically for the fresh feed flow rate $\left(F_{0}\right)$ changes. Assuming constant $x_{\mathrm{D}}, x_{\mathrm{B}}$ and $V_{R}$, from equations (1)-(4), we have:

$$
\left(\frac{F}{\bar{F}}\right)_{\mathrm{c}}=\frac{\bar{x}_{\mathrm{D}}-\bar{z}}{\bar{x}_{\mathrm{D}}-r \bar{z}} r
$$

where the overbar denotes nominal steady-state value, $r$ is $\left(F_{0} / \bar{F}_{0}\right)$ and the subscript $\mathrm{c}$ denotes the conventional structure. Similarly, the distillate flow rate, reactor composition $(z)$ and reactor holdup $\left(V_{\mathrm{R}}\right)$ can also be expressed as:

$$
\begin{gathered}
\left(\frac{D}{\bar{D}}\right)_{\mathrm{c}}=\left[\frac{\bar{x}_{\mathrm{D}}-\bar{z}}{\bar{x}_{\mathrm{D}}-r \bar{z}}\left(1+\frac{\bar{F}_{0}}{\bar{D}}\right)-\frac{\bar{F}_{01}}{\bar{D}}\right] r \\
\left(\frac{z}{\bar{z}}\right)_{\mathrm{c}}=r \\
\left(\frac{V_{\mathrm{R}}}{\bar{V}_{\mathrm{R}}}\right)_{\mathrm{c}}=1
\end{gathered}
$$

Equation (13) clearly shows that the constant level practice of the conventional structure results in an "under-performance" of the reactor, e.g., per cent change in $z$ is proportional to per cent change in $F_{0}$. This, subsequently, requires a column-overwork. First, one can observe an ultimate constraint imposed on this structure from equation (11) and (12). If we have:

$$
r=\frac{\bar{x}_{\mathrm{D}}}{\bar{z}}=1.9
$$

the distillate flow rate (or the column feed flow rate) goes to infinity as can be seen from equation (12). Obviously, any process variable has a physical constraint, e.g., the maximum flow capacity in the distillate is often designed as twice of $\bar{D}$. That means the operability (throughput handling ability) of the conventional structure is much smaller then the data from equation (15) (Fig. 6). This is exactly the snowball effect pointed out by Luyben (1994).

In order to maintain the desired separation under a throughput increase, the distillation column has to handle both the feed composition $(z)$ and feed flow rate $(F)$ increases. Therefore, both the vapor boilup $(V)$ and reflux flow rate $(R)$ increase quadratically for a linear increase in $F_{0}$ as shown in Fig. 6. Since only a fixed amount of product $\left(B=F_{01}\right)$ is taken out of the column, most of these flow rate increases recycle back to the reactor. Figure 6 shows the changes in the process variables for a range of changes in $F_{0} / \bar{F}_{01}$ (from 0.1 to 1.6 ).

The process behavior shown here is very different from cascade units or individual units. Furthermore, this result comes from an almost unnoticed reason that the reactor does not keep up to its performance for a throughput change. Actually, to some extent, equation (6) does reveal this fact. For a given product specification $\left(x_{\mathrm{B}}\right)$, the load changes in $F_{0}$ and $z_{0}$ can only be handled via $V_{\mathrm{R}}, k$ or $z$. A constant holdup $\left(V_{\mathrm{R}}\right)$ with a constant reactor temperature control strategy (a common practice for cascade units) results in the column overwork situation (i.e., column feed composition $z$ absorbing all the change from load variables)

Similar behavior can also be observed for fresh feed composition changes. Figure 7 shows how process variables vary for a range of $z_{0}$ changes. The Appendix gives analytical expression for the changes in some of the proccss variables.

3.1.2. Reactor overwork. Luyben (1994) realizes the situation of column overwork and the potential problem of snowball effect on the recycle stream and a new control structure is proposed (Fig. 5b). In the Luyben structure, the reactor holdup is adjusted for known changes in fresh feed flow $\left(F_{01}\right)$ and feed composition $\left(z_{11}\right)$. This, in fact, overcomes the reactor under-performance problem. However, a unique feature of the Luyben structure is that the reactor effluent flow rate $(F)$ is kept constant using a flow controller (Fig. 5b). This implies that, even under throughput changes, the column feed flow rate is not allowed to change. As for the column control, both the top and bottoms compositions are controlled by manipulating $R$ and $V$, respectively, as shown in Fig. $5 b$. Despite the fact that the fresh feed flow is used as a manipulated variable in the Luyben structure, 

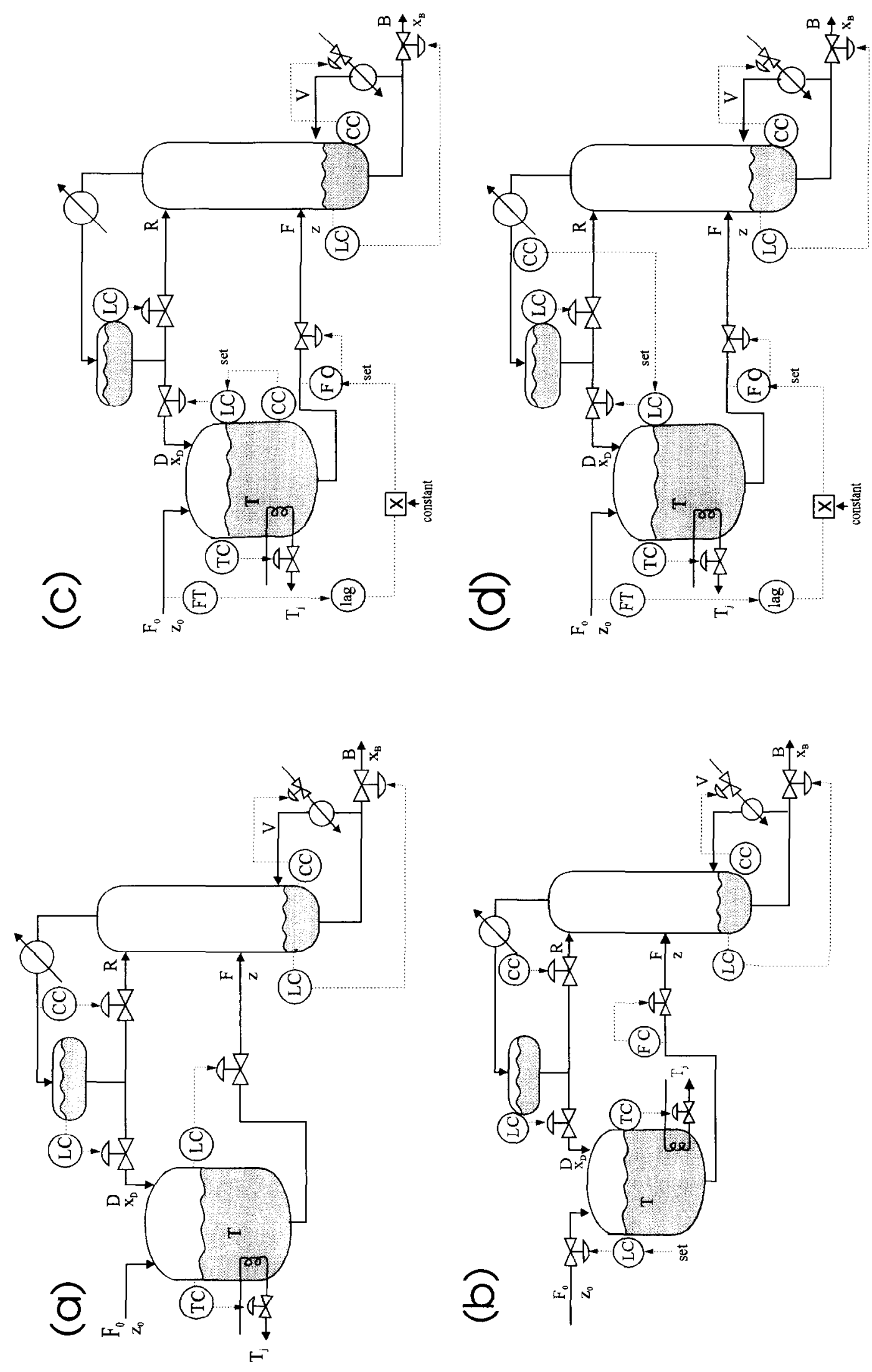

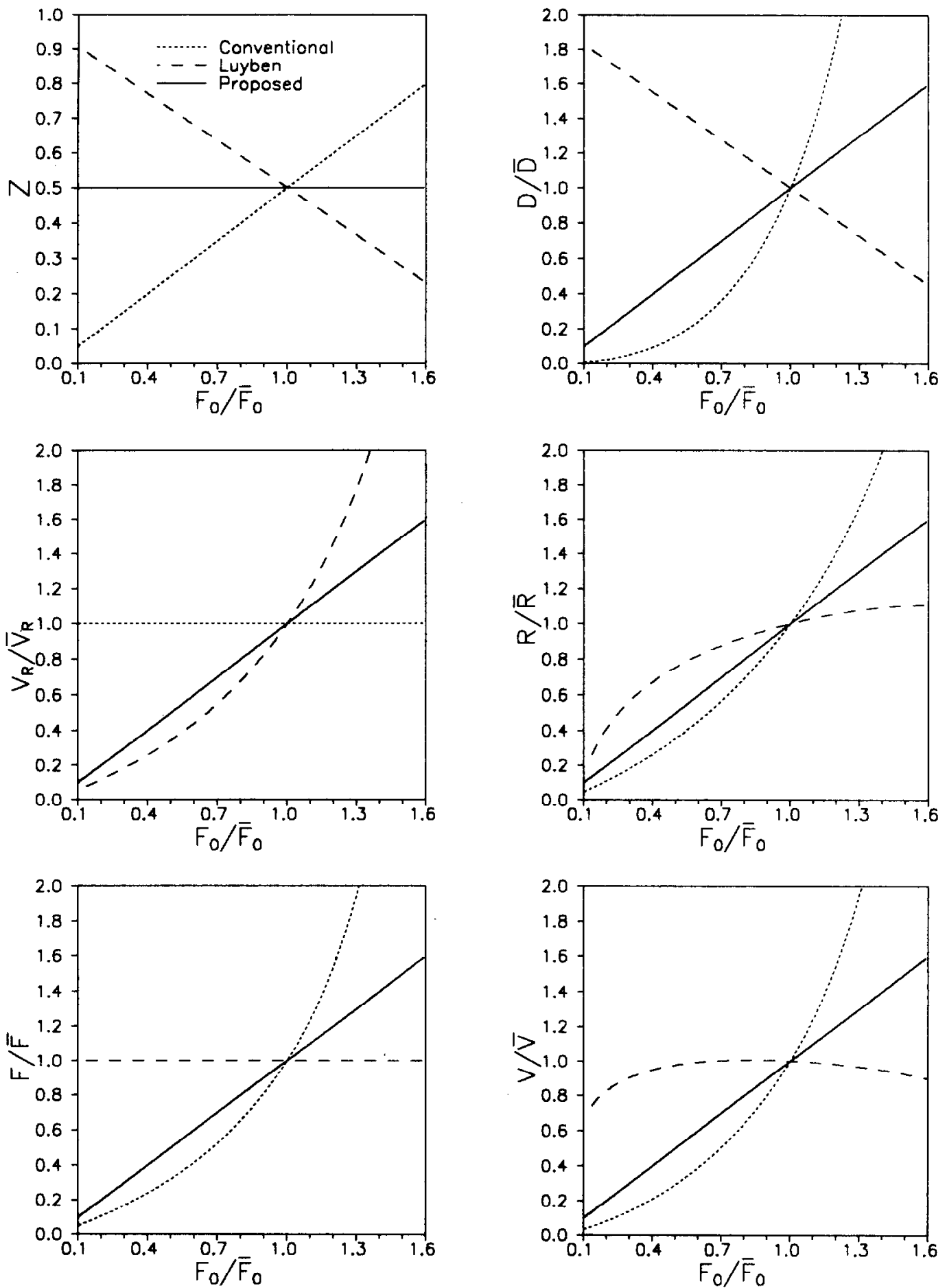

Fig. 6. Steady-state values of process variables for a range of $F_{01}$ changes under different control structures. 

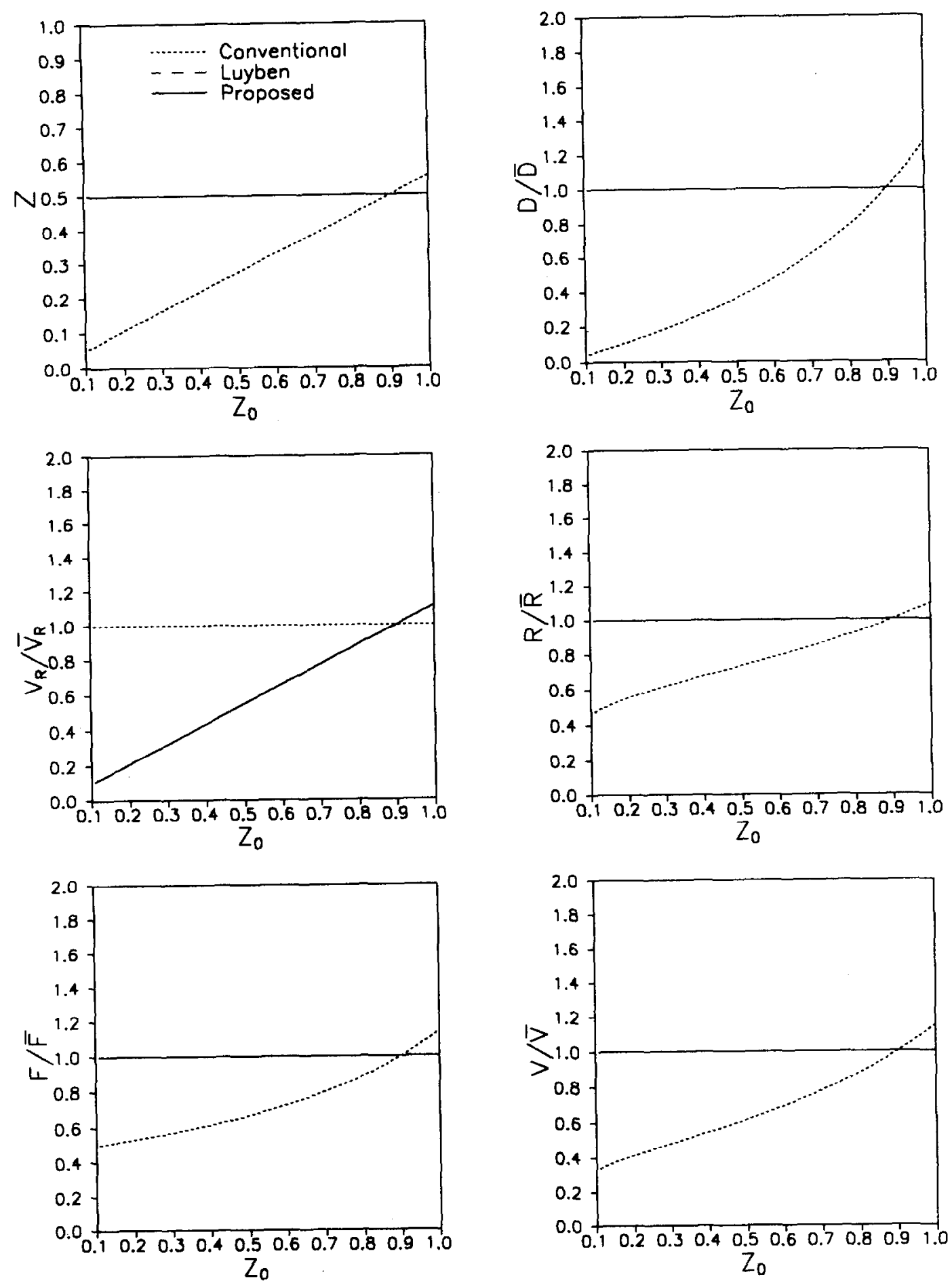

Fig. 7. Steady-state values of process variables for a range of $z_{11}$ changes under different control structures. 
the throughput change is accomplished in an indirect manner, i.e., by adjusting the reactor level.

Again, the process variables can be expressed analytically by solving equations (1)-(4). The variables

kept constant are: $x_{1}, x_{\mathrm{B}}$ and $F$. For throughput $\left(r=F_{11} / \tilde{F}_{11}\right)$ changes, corresponding process variables are:

$$
\begin{gathered}
\left(\frac{F}{\bar{F}}\right)_{\mathrm{L}}=1 \\
\left(\frac{D}{\bar{D}}\right)_{\mathrm{L}}=\left(1+\frac{\bar{F}_{10}}{\bar{D}}\right)-\left(\frac{\bar{F}_{11}}{\bar{D}}\right) r \\
\left(\frac{z}{\bar{z}}\right)_{\mathrm{L}}=\frac{\bar{x}_{\mathrm{D}}}{\bar{z}}-\left(\frac{\bar{x}_{\mathrm{D}}}{\bar{z}}-1\right) r \\
\left(\frac{V_{\mathrm{R}}}{\bar{V}_{\mathrm{R}}}\right)_{\mathrm{L}}=\frac{\bar{z}}{\bar{x}_{\mathrm{D}}-\left(\bar{x}_{\mathrm{D}}-\bar{z}\right) r} r
\end{gathered}
$$

where the subscript $L$ denotes the Luyben structure. Figure 6 shows the changes in the process variables for a range of throughput changes $\left(F_{11} / F_{0}=0.1-1.6\right)$. The results clearly show that the variable reactor holdup structure does alleviates the snowball effect on the recycle stream (e.g., $D / \bar{D}$ in Fig. 6). However, in this variable-reactor-level control structure, an important question to ask is that: what is an appropriate reactor holdup? For an individual reactor, the reactor performance is maintained by keeping reactor composition ( $z$ ) constant. Since $F$ is kept constant, an increase in $V_{\mathrm{R}}$ (as a result of $F_{0}$ increase) leads to a larger residence time $\left(V_{\mathrm{R}} / F\right)$ and, subsequently, results in a belter conversion (a smaller $z$ ). Comparing this with the conventional structure (Fig. 6), the reactor composition $(z)$ is over-adjusted and, subsequently, the process variables in the column remain fairly constant for throughput changes. For this reactor overwork situation, the snowball effect, in fact, remains. Instead of significant changes in the recycle stream, the reactor holdup $\left(V_{R}\right)$ changes significantly for a throughput increase (Fig. 6). The ultimate constraint imposed on the Luyben structure is $V_{\mathrm{R}}$ as shown in equation (18). If

$$
r=\frac{\bar{x}_{1)}}{\bar{x}_{1}-\bar{z}}=2.09
$$

the reactor holdup goes to infinity (equation 19). Obviously, in practice, the throughput handing ability is much smaller then this value (e.g., a finite capacity imposed on the reactor holdup). Therefore, it becomes obvious that the snowball effect does not disappear for throughput changes. It appears in the reactor holdup $\left(V_{\mathrm{R}}\right)$ instead of in the recycle flow rate.

In the Luyben structure. the fresh feed composition disturbance can be handled by adjusting the reactor holdup (Fig. 7). Moreover, the following process variables (e.g., $z, D, F, R, V$ ) remain unchanged for fresh feed composition disturbances. Appendix gives the analytical expression for the process variables under $z_{11}$ changes.

\subsection{Balanced scheme}

From the analyses of the conventional structure and Luyben structure, it becomes clear that if the load disturbance are not handled evenly by these two units, this imbalance grows exponentially via the recycle structure. This, consequently, leads to the snowball effect and, more importantly, results in limited disturbance rejection capability. That is a unique feature of plantwide control. Therefore, care has to be taken in devising control structure by distibuting extra work evenly between these two process units.

For the reactor control, a measure of performance is the reactor composition. Therefore, the reactor composition can be controlled by adjusting reactor holdup $\left(V_{\mathrm{R}}\right)(\mathrm{Fig} .5 \mathrm{c})$. In doing this, the reactor level grows linearly for fresh feed flow rate changes as indicated by equations (9) and (10). As for the distillation column control, since both the column feed flow rate $(F)$ and composition $(z)$ are controlled (in feedforward or feedback manner) for external load changes, only single-end composition control in the separator is sufficient to hold top and bottoms compositions. Once the reactor/separator is controlled in this way, the separator shares its work under throughput change. It is worthwhile to mention that, in this structure, the reactor and separator is treated as a complete process unit and the control system is designed accordingly. For example, the recycle flow $(D)$ is adjusted by measuring the reactor level (Fig. 5c). This design concept indicates an important point in plantwide control: treat the whole plant as a unit instead of design the control for individual unit and put them together to form a plantwide control structure. For this control structure, analytical expression for process variables under throughput changes can also be derived from equations (1)-(4). By assuming $x_{\mathrm{B}}$ and $z$ constant, 
and $F$ changed proportional to $F_{t h}$ the process variables of interest become:

$$
\begin{aligned}
& \left(\begin{array}{l}
F \\
\bar{F}
\end{array}\right)_{\mathrm{b}}=r \\
& \left(\frac{D}{\bar{D}}\right)_{\mathrm{h}}=r \\
& \left(\frac{z}{\bar{z}}\right)_{\mathrm{b}}=1 \\
& \left(\frac{V_{\mathrm{R}}}{\bar{V}_{\mathrm{R}}}\right)_{\mathrm{h}}=r
\end{aligned}
$$

where $r$ is the relative change in the fresh feed flow rate $\left(F_{1} / \bar{F}_{01}\right)$ and the subscript $b$ denotes the balanced control structure. It immediately becomes clear that, comparing this with the other two structures, ultimate constraint (e.g., equations 11 and 12 or 20) does not exist in this structure. That gives a better operability. Comparison is made for these three control structures under throughput changes. The results (Fig. 6) clearly indicate that, for the balanced control structure, the extensive variables (e.g., $V_{\mathrm{R}}, F, V, R$, etc.) changes in proportion to throughput $\left(F_{11}\right)$ changes. In other words, both subunits share their work to overcome throughput changes. On the other hand, if one of the subunit overworks, the manipulated variables (or process variables) (e.g., $D$ for conventional structure or $V_{\mathrm{R}}$ for Luyben structure) could be saturated for a small range of load changes. Figure 7 shows how these three control structures handle fresh feed composition changes. For both the Luyben and the balanced structures, $Z_{0}$ changes are handled by the reactor and these two structures show identical results. The Appendix gives the derivation for fresh feed composition changes.

Notice that the configuration shown in Fig. $5 \mathrm{c}$ (structure $B_{1}$ ) is not the only possible choice to achieve this balance in plantwide control. An alternative is to keep the distillation top composition constant by changing the reactor level set point as shown in Fig. $5 d$ (structure $B_{2}$ ). This control structure gives exactly the same disturbance rejection capability as the other balanced structure (Fig. 6). Equation (7) clearly shows that as long as the ratio $F / F_{0}$ is kept constant, holding any two compositions (out of $x_{1}, x_{\mathrm{B}}$ and $z$ ) constant will maintain the third composition at its set point. Therefore, a more appropriate control structure will be decided from these two alternatives according to their dynamic properties. Note that two composition analysers are required for all control structures mentioned (Fig. 5).

\section{STEADY-STATE ANALYSES}

\subsection{Controllability}

The relative gain array (RGA) of Bristol (1966) was employed to analyse the interaction (Papadourakis et $a l ., 1987)$ and to access the controllability of plantwide control systems (Luyben and Floudas, 1994). It is well known that RGA is an interaction measure for multivariable systems (McAvoy, 1983) and it can be used to test the integral controllability of closed-loop system. (Morari and Zafiriou, 1990; Yu and Fan, 1990).

There are three major loops in this plantwide structure (two composition loops, $x_{13}$, and $x_{1}$ or $x_{13}$ and $z$, and one temperature loop, T), $3 \times 3$ RGAs can be obtained for these four control structures (Fig. 5) from steady-state rating programs (Table 2). The results show that all these four structures $(C, L$, $B_{1}$ and $B_{2}$ ) are decentralized integral controllable (Yu and Fan, 1990). That is, the controller gains for any of these loops can be reduced arbitrarily to zero (manual mode) without causing instability. Therefore, all three control structures are failure tolerant. This guarantees the integrity of the control system.

Furthermore, the closed-loop interaction can also be analysed using RGA. Since the temperature loop is much faster than the composition loops (as will be shown later), it is easier to interpret the interaction by looking the composition loops (assuming constant $T$ ). Table 2 gives the RGA's for the reduced system. Before looking at the plantwide system, it should be noticed that the RG $\wedge$ for the column itself (under $R-V$ control) (Fig. 2) is:

$$
\Lambda=\left[\begin{array}{cc}
x_{\mathrm{B}} & x_{\mathrm{D}} \\
6.8 & -5.8 \\
-5.8 & 6.8
\end{array}\right] \quad V
$$

Obviously, Table 2 shows that the relative gain $\left(\lambda_{i j}\right.$ 's) for Luyben's structure $\left(\lambda_{11}=12.16\right)$ is much larger than that of the column alone $\left(\lambda_{11}=6.8\right)$ or the conventional structure $\left(\lambda_{11}=2.78\right)$. That means if the steady-state interaction is the only indication of controllability, the conventional structure is a better choice. Table 2 also shows that the balanced structure has very different characteristics, i.e., $\lambda_{11}=$ $0.78<1$. The RGA for this structure looks very much like a $D-V$ (distillate and vapor boil-up) controlled system. This is quite the case. For the control structure $B_{2}$, consider the case when a step increase in $V$ is made. Since $D$ is manipulated by the reactor holdup, the reflux flow increases while keeping $D$ constant. Therefore, the steady-state gains for these two compositions have different sign for a 
Table 2. RGA lor different control structures with different assumption

\begin{tabular}{|c|c|c|c|c|c|c|}
\hline \multirow[b]{2}{*}{ Scheme } & \multirow{2}{*}{$\begin{array}{l}\text { Controlled } \\
\text { variable }\end{array}$} & \multicolumn{3}{|c|}{ Manipulated variable } & \multicolumn{2}{|c|}{$\begin{array}{l}\text { Manipulaled } \\
\text { variable" }\end{array}$} \\
\hline & & $V$ & $R$ & $T_{1}$ & $V$ & $R$ \\
\hline C & $\begin{array}{l}x_{13} \\
x_{11} \\
r\end{array}$ & $\begin{array}{r}3.3013750 \\
-2.032009 \\
-0.27(1760\end{array}$ & $\begin{array}{r}-2.078648 \\
3.1012975 \\
0.1175672\end{array}$ & $\begin{array}{r}-0.225111 \\
0.030024 \\
1.195088\end{array}$ & $\begin{array}{r}2.78 \\
-1.78\end{array}$ & $\begin{array}{r}-1.78 \\
2.78\end{array}$ \\
\hline$\left.(C)_{l}\right)$ & $\stackrel{x_{B}}{T}$ & $\begin{array}{r}1.246 .383 \\
-0.246 .383\end{array}$ & $\begin{array}{r}-11.2460 .383 \\
1.246 .383\end{array}$ & & 1.0 & \\
\hline$(C)_{k}$ & $\stackrel{x_{13}}{T}$ & $\begin{array}{r}1.184476 \\
-11.184476\end{array}$ & $\begin{array}{c}-0.184476 \\
1.84476\end{array}$ & & 1.0 & \\
\hline$(C)_{k R}$ & $\frac{x_{13}}{T}$ & $\begin{array}{r}1.2017454 \\
-11.2017454\end{array}$ & $\begin{array}{r}-0.207454 \\
1.207444\end{array}$ & & 1.0 & \\
\hline$(C)$ & $\frac{x_{k}}{T}$ & $\begin{array}{r}1.246386 \\
-11.240 .386\end{array}$ & $\begin{array}{r}-0.246 .386 \\
1.246 .386\end{array}$ & & I.0 & \\
\hline L & $\begin{array}{c}x_{H} \\
x_{11} \\
T\end{array}$ & $\begin{array}{r}9.15064 \\
-8.21615 \\
0.1560106\end{array}$ & $\begin{array}{r}-8.12565 \\
8.916006 \\
0.209647\end{array}$ & $\begin{array}{c}-0.013399 \\
0.300144 \\
0.733847\end{array}$ & $\begin{array}{r}12.16 \\
-11.6\end{array}$ & $\begin{array}{r}-11.16 \\
12.16\end{array}$ \\
\hline & & $V$ & $V_{\mathrm{R}}^{\mathrm{K}-1}$ & $T_{1}$ & $V$ & $V_{\mathrm{R}}^{\mathrm{Cl}}$ \\
\hline$B_{1}$ & $\begin{array}{c}x_{\mathrm{B}} \\
z\end{array}$ & $\begin{array}{c}0.968 \\
0.032 \\
-0.0060022\end{array}$ & $\begin{array}{l}0.147 \\
0.512 \\
0.341\end{array}$ & $\begin{array}{r}-0.114 \\
0.455 \\
0.659\end{array}$ & $\begin{array}{l}0.78 \\
0.22\end{array}$ & $\begin{array}{l}10.22 \\
0.78\end{array}$ \\
\hline $\mathrm{B}_{?}$ & $\begin{array}{l}x_{13} \\
r_{13} \\
T\end{array}$ & $\begin{array}{r}0.731823 \\
0.268179 \\
-0.01012\end{array}$ & $\begin{array}{l}0.271457 \\
0.387574 \\
0.34(10964\end{array}$ & $\begin{array}{c}-0.1000328 \\
0.344242 \\
0.6590\end{array}$ & $\begin{array}{l}0.59 \\
11.41\end{array}$ & $\begin{array}{l}0.41 \\
0.59\end{array}$ \\
\hline
\end{tabular}

"Assuming constant reactor lemperature.

change in $V$. The result is different from the control structures (e.g., conventional or Luyben structure) showing $R-V$ control type of behavior. The steadystate gain matrix is:

$\left[\begin{array}{l}x_{13} \\ x_{13}\end{array}\right]=\left[\begin{array}{rr}-4.1 \times 10^{-5} & -8.3 \times 10^{-5} \\ 2.3 \times 10^{-5} & -1.6 \times 10^{-5}\end{array}\right]\left[\begin{array}{c}V \\ V_{\mathrm{R}}^{\mathrm{cl}}\end{array}\right]$.

The second column of the gain matrix looks more like the steady-state gains for feed composition change. For a change in $V_{\mathrm{R}}$ results in a change in $z$ and subsequently affects both $x_{13}$ and $x_{1}$. The $D-V$ structure has a larger closed-loop gain and, therefore, $\lambda_{11}$ is smaller than unity $\left(\lambda_{11}<1\right)$. The RGA analyses indicate that the input-output pairing is correct for the balanced structure. Furthermore, one can obtain control structures without any interaction by controlling one-end (bottoms composition) only. Figure 8 shows four possible structures that only $x_{13}$ is controlled and $x_{12}$ is left uncontrolled by fixing one flow rate or ratio (e.g.. $D, R, R R$ or $F$ ) constant. From the interaction point of view, these four structures are better choices (Table 2), since the relative gain is unit for single-input-singleoutput systems.

If the interaction is the sole measure of controllability, then the least interacting control structure, e.g., single-end control or the conventional structure. should be the candidate control structure. However, the disturbance handling capability seems to be a more important factor is plantwide control structure selection.

\subsection{Operability}

For the control structures studied (Table 3 ), the effects for a range of load changes $\left(z_{11}\right.$ and $\left.F_{10}\right)$ can be calculated from the steady-state equations. Notice that, in the computation, no constraint is placed on the flow rates or levels. Therefore, the range of load changes can be handled by the control structure (rangeability) comes from the fact that the product specification(s) (e.g., $x_{\mathrm{B}}$ or $x_{\mathrm{D}}$ and $x_{\mathrm{B}}$ ) simply cannot be met. Table 3 gives the rangeabilities for $F_{11}$, and $z_{11}$ changes for all these seven control structures. It is interesting to note that some of the structures give unreasonably small rangeabilities, e.g., $\left(C_{b}\right)$ and (C) ${ }_{r}$, for fresh feed flow changes. For example, the structure $(\mathrm{C})_{h}$, can handle only $3 \%$ throughput increase, despite the fact this structure does not have any interaction problem. The reason is that for a positive change in the throughput. the reactor composition $(z)$ changes proportionally. Therefore, the total light component going into the column increases quadratically which cannot be handled by the column if both $x_{B}$ and $D$ are fixed. That is the purity of the light component on the top of the column reaches $100 \%$ for a $3 \%$ increase in $F_{11}$. A similar limitation is observed in the $(C)_{r}$ structure. For an increase in $F_{0}$, the distillate flow rate has to be reduced for the fixed reaction effluent flow rate $(F)$ configuration (Fig. 8d). Despite the fact that $F$ is 

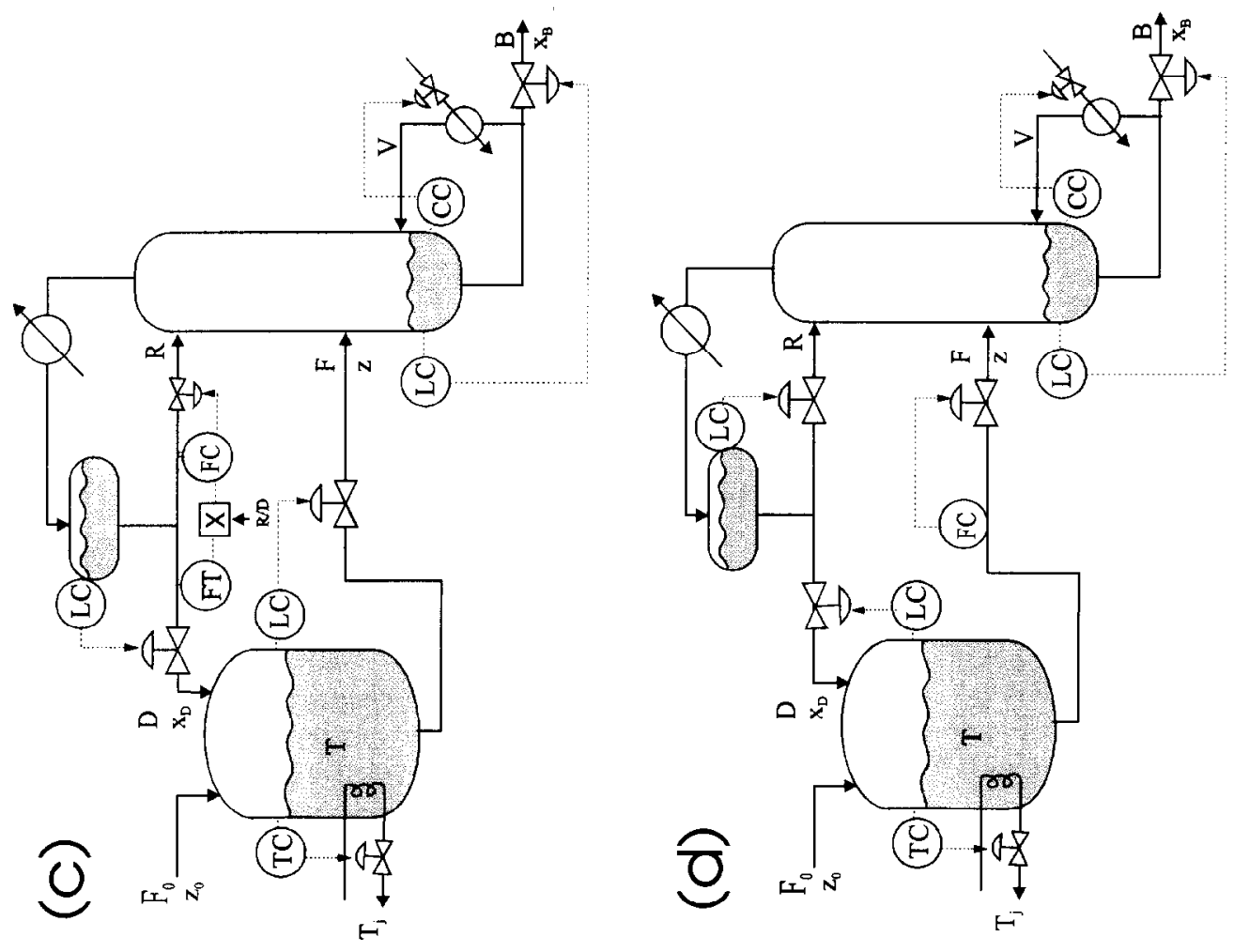

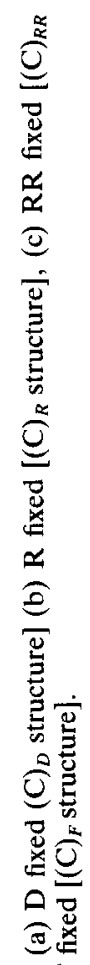
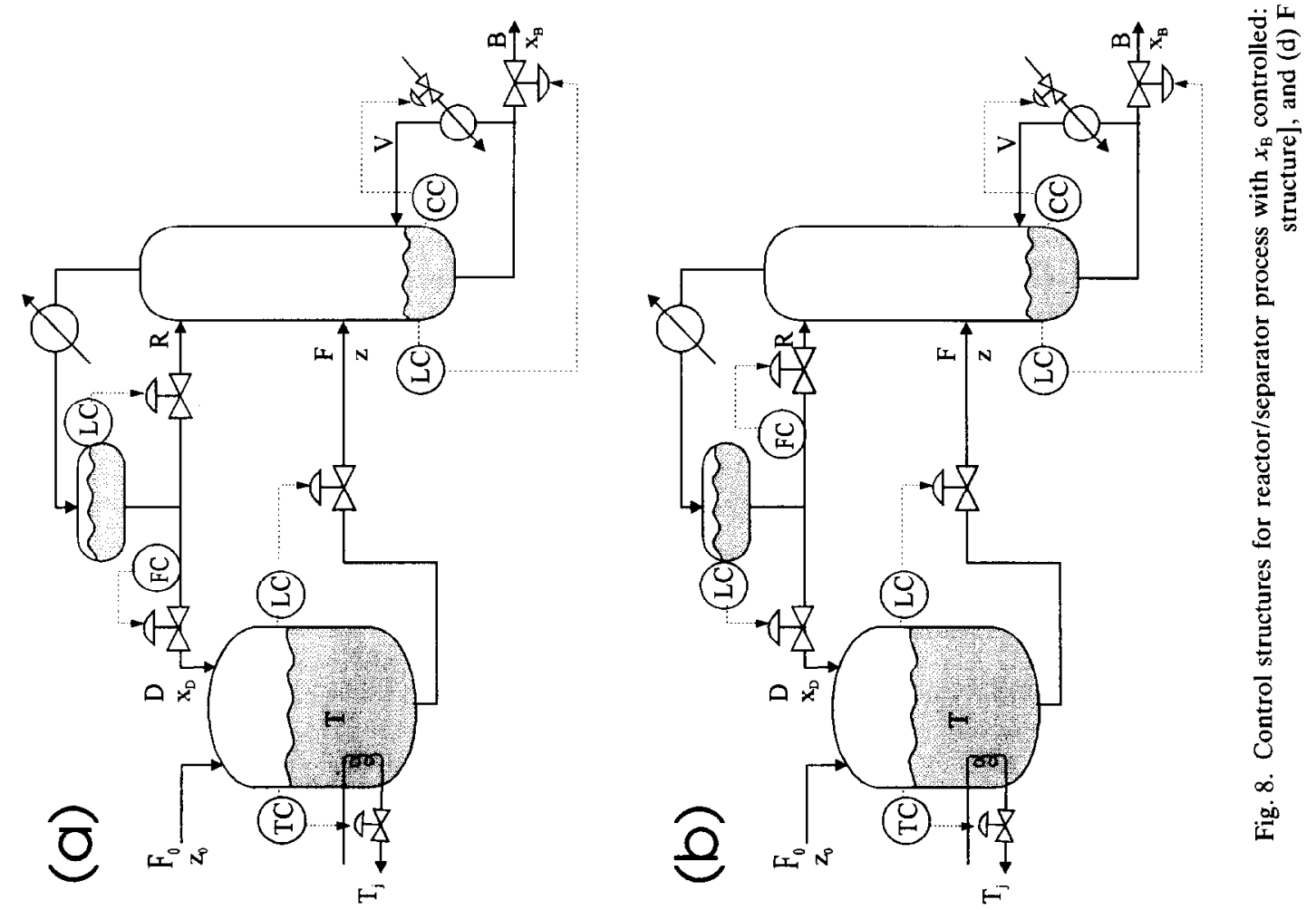
Table 3. Rangeability analyses for different control structures with different load changes

\begin{tabular}{llllll}
\hline \multirow{2}{*}{ Scheme } & $\begin{array}{c}\text { Disturbance } \\
\text { variable }\end{array}$ & $(z)_{\max }$ & $\left(z_{0}\right)_{\min }$ & $\left(\frac{F_{0}}{\bar{F}_{0}}\right)_{\max }$ & $\left(\frac{F_{0}}{\bar{F}_{0}}\right)_{\min }$ \\
\hline \multirow{4}{*}{ Conventional } & $\mathrm{C}$ & 1.0 & 0.153 & 1.801 & 0.131 \\
& $(\mathrm{C})_{D}$ & 0.938 & 0.2898 & 1.03 & 0.64 \\
& $(\mathrm{C})_{R}$ & 1.0 & 0.163 & 1.9 & 0.2136 \\
& $(\mathrm{C})_{R R}$ & 1.0 & 0.162 & 1.99 & 0.3 \\
\multirow{2}{*}{ Luyben } & $(\mathrm{C})_{+}$ & 0.945 & 0.207 & 1.03 & 0.67 \\
Balanced $\left(\mathrm{B}_{1}\right.$ and $\left.\mathrm{B}_{2}\right)$ & 1.0 & 0.189 & 15.12 & 0.0047 \\
\hline
\end{tabular}

flow controlled, the total light component $(z \cdot F)$ going into the column increases as the result of increased purity in $x_{\mathrm{D}}$. This structure can only tolerate a small increase in $F_{0}$ (decrease in $D$ ), since $x_{\mathrm{D}}$, since $x_{\mathrm{D}}$ is limited by its physical constraints $\left(x_{\mathrm{D}} \leqslant 1\right)$. This can be shown by rearranging equations (5) and (6). Denoting $r$ as the dimensionless ratio of the fresh feed flow rate, we have:

$$
r=\frac{\bar{F} x_{\mathrm{D}}}{\bar{F}_{0}\left(x_{\mathrm{D}}-\bar{x}_{\mathrm{B}}\right)+\bar{F} \bar{z}} .
$$

Substituting the nominal steady-state value for $\bar{F}=$ $960.378, \bar{F}_{0}=460, \bar{x}_{\mathrm{B}}=0.0105$, and $\bar{z}=0.5$ and the limiting value $x_{D}=1$ into equation (27), one obtains:

$$
r=1.03 \text {. }
$$

Obviously, this shows a complete lack of operability in plantwide control. Unfortunately, the interaction analysis does not give any indication of rangeability problem.

Again, the balanced schemes give the largest rangeability for throughput changes as shown in Table 3. Furthermore, the Luyben structure has a larger rangeability than the conventional scheme for $F_{0}$ changes. The results presented here are in contradiction with that from interaction analyses. Therefore, a tradeoff has to be made between interaction and operability. All the control structures with $x_{\mathrm{B}}$ and $x_{\mathrm{D}}$ controlled handle $z_{0}$ changes equally well. From the on-going analyses, it becomes obvious that the balanced structure is a better choice from the steady-state point of view.

\section{DYNAMICS AND CONTROL}

The dynamics of the reactor/separator process is analysed using a series rigorous dynamic simulations. The reactor is a CSTR with the reactor temperature controlled by the cooling water flow rate. The assumptions of theoretical tray, equimolar overflow and constant relative volatility are made in modeling the distillation column. The differential equations are similar to that of Luyben (1990; pp. 64 and 70). Parameters characterizing dynamic behavior, e.g., holdups in column and reactor, are given in Table 1. Constraints are placed on the flow rates and levels. The maximum flow rate and holdup are set to be twice the nominal steady-state values except for the fresh feed flow rate. It was set to be three times of the steady-state value. Six minutes of analyser dead time and 1 min of temperature measurement lag are assumed in the composition loop and temperature loop, respectively.

\subsection{Controller tuning}

Despite the fact that many methods have been proposed for the tuning of multivariable systems (Luyben, 1986; Marino-Galarraga et al. 1987; Shen and $\mathrm{Yu}, 1994$ ), little is said about the tuning of plantwide control structure in a systcmatic manner. Several authors (Luyben, 1993a-c; Price et al., 1993) find ultimate gain $\left(K_{\mathrm{u}}\right)$ and ultimate frequency $\left(\omega_{\mathrm{n}}\right)$ first followed by Ziegler-Nichols type of tuning method in their plantwide control systems. Initial response tuning method of Tyreus and Luyben (1992) is an alternative in plantwide control. Since typically many loops are involved in a plantwide system, an important question to be answered is that which loop (or group of loops) should be tuned first and by what method. That is, what is the tuning sequence (e.g., arranged by unit, by properties or by speed of response). One thing is clear, however, the inventory loops should be under control when the quality loops are tuned (Price et al., 1993; McAvoy and Ye, 1994).

5.1.1. Inventory control. In this work, the inventory in the system is maintained through three level loops (Fig. 5). The level loops are tuned first followed by finding the tuning constants for the composition and temperature loops. Since the holdups; in the column $\left(M_{\mathrm{D}}\right.$ and $\left.M_{\mathrm{B}}\right)$ is an order of magnitude smaller than that of the reactor holdup $\left(V_{R}\right)$ (Table 1), perfect level control is assumed in these two level loops (controlling $M_{\mathrm{D}}$ and $M_{\mathrm{B}}$ ).

The averaging level control of Cheung and Luyben (1979) is used for the tuning of the reactor level loop. For the conventional and Luyben structures, a PI (proportional-integral) controller is employed for the reactor level control. First, the closed-loop time constant is set to be a ratio $(\mathbf{1 0 \%})$ of the reactor residence time and a damping ratio $(\zeta=0.707)$ is specified for the closed-loop characteristic equation. Following the tuning chart of Cheung and Luyben (1977), the controller gain $\left(K_{c}\right)$ and reset time $\left(\tau_{1}\right)$ can be found directly. The tuning constants for the level loops are given in Table 4 . For the balanced control structures, the reactor level is cascaded by top composition, and, therefore, a P 
Table 4. Ultimate properties and controller parameters for different control structures

\begin{tabular}{|c|c|c|c|c|c|}
\hline Structure & $\begin{array}{l}\text { Parameter } \\
\text { pairing }\end{array}$ & $K_{\mathrm{u}}$ & $\omega_{\mathrm{u}}{ }^{a}$ & $K_{\mathbf{c}}^{b}$ & $\tau_{\mathrm{I}}^{c}$ \\
\hline \multirow{3}{*}{ Conventional } & $\begin{array}{c}\text { Temp. loop } \\
T-T_{j}\end{array}$ & 17.081 & 94.06 & 5.69 & 8.0 \\
\hline & $\begin{array}{c}\text { Comp. loop } \\
x_{\mathrm{B}}-V\end{array}$ & -2.24 & 13.0982 & -0.75 & 57.6 \\
\hline & $\begin{array}{c}\text { Comp. loop } \\
x_{\mathrm{D}}-R\end{array}$ & 0.92 & 9.827 & 0.31 & 76.7 \\
\hline & Level loop & & & -5.66 & 21.2 \\
\hline \multirow{4}{*}{ Luyben's } & $\begin{array}{c}\text { Temp. loop } \\
\quad T-T\end{array}$ & 17.051 & 94.2 & 5.68 & 8.0 \\
\hline & $\begin{array}{c}\text { Comp. loop } \\
x_{B}-V\end{array}$ & -1.60 & 9.83 & -0.53 & 76.7 \\
\hline & $\begin{array}{c}\text { Comp loop } \\
x_{\mathrm{D}}-R\end{array}$ & 0.81 & 8.74 & 0.27 & 86.4 \\
\hline & Level loop & & & 9.43 & 44.3 \\
\hline \multirow{3}{*}{ Balanced 1} & $\begin{array}{c}\text { Temp. loop } \\
T-T_{\mathrm{j}}\end{array}$ & 17.064 & 94.2 & 5.69 & 8.0 \\
\hline & $\begin{array}{c}\text { Comp. loop } \\
x_{\mathrm{B}}-V\end{array}$ & -9.89 & 19.592 & -3.30 & 38.4 \\
\hline & $\underset{z-V_{\mathbf{R}}^{\text {set }}}{\text { Comp. loop }}$ & -0.16 & 2.4962 & & 125.9 \\
\hline \multirow{5}{*}{ Balanced 2} & Level loop & & & 40.29 & \\
\hline & $\begin{array}{c}\text { Temp. loop } \\
T-T_{j}\end{array}$ & 16.996 & 93.919 & 5.67 & 8.0 \\
\hline & $\begin{array}{c}\text { Comp. loop } \\
x_{\mathrm{B}}-V\end{array}$ & -9.81 & 20.061 & -3.27 & 37.6 \\
\hline & $\begin{array}{c}\text { Comp loop } \\
x_{\mathrm{D}}-V_{\mathrm{R}}^{\text {set }}\end{array}$ & -0.06 & 6.874 & -0.03 & 45.7 \\
\hline & Level loop & & & 29.31 & \\
\hline
\end{tabular}

${ }^{a} \mathrm{Rad} / \mathrm{min}$.

Transmitter spans: $x_{\mathrm{D}}, x_{\mathrm{B}}: 0.1$ mol fraction; $z$ : 0.2 mole fraction; level: twice nominal steady-state holdup; valve gain: twice nomina steady-state flow rate except for fresh feed flow, (three times nominal steady-state flow rate). ${ }^{c}$ Min.

(proportional)-only controller is sufficient to maintain the composition set point. Since a P-only controller is employed is the reactor level control for the balanced structure, the tuning constant $K_{\mathrm{c}}$ is found by setting the closed-loop time constant to be a ratio (roughly $3 \%$ ) of the residence time (Table 4). It should be emphasized that the tuning of the reactor level loop can affect the tuning constants of the quality loops especially for the Luyben and the balanced structures. The reason is quite obvious, these two structure manipulate the reactor level for quality control.

5.1.2. Flow feedforward. Since a ratio control is involved in the two balanced control structures (Fig. $5 c, d$ ), a dynamic element is placed in the feedforward path. This is a "lag" device with the time constant set to be $10 \%$ of the residence time.

Furthermore, the dynamic behavior of the two balanced structure ( $B_{1}$ and $B_{2}$ ) is not quite the same. Consider the case when a step change is made in $V_{\mathrm{R}}^{\text {set. }}$. Figure 9 shows the responses of $x_{\mathrm{D}}$ and $z$. It is clear that the reactor composition $z$ goes through an inverse response, while $x_{\mathrm{D}}$ showing a little underdamped step response. It is well known that the non- minimum phase behavior of $z / V_{\mathrm{R}}^{\text {set }}$ cannot be removed via control. Therefore, the balanced $B_{2}$ control structure is selected from the dynamic response point of view and it is used for subsequent comparisons (with other control structures).

5.1.3. Quality loop. Once the inventory is under control, the tuning constants for the reactor temperature and distillation composition loops can be found. PI controllers are employed for quality control. These threc loops are tuned using the multivariable autotuner of Shen and Yu (1994). The relay-feedback MIMO autotuner proceeds the tuning sequentially and the sequence is repeated until the corresponding tuning constants are relatively close between sequences.

Let us take the tuning of the conventional structure as an example (Fig. 10). Initially, the relay feedback test is performed on the $T-T_{\text {, loop and }}$ sustained oscillation is generated as shown in Fig. 10. The ultimate gain $K_{\mathrm{u}}$ can be found from system responses.

$$
K_{\mathrm{u}}=\frac{4 h}{\pi a}
$$

where $a$ is the amplitude of the output and $h$ is the relay height. The ultimate period $\left(P_{\mathrm{u}}\right)$ can be read off from system responses. Once $K_{\mathrm{u}}$ and $P_{\mathrm{u}}$ are available, $K_{\mathrm{c}}$ and $\tau_{\mathrm{I}}$ can be found according to:

$$
\begin{gathered}
K_{\mathrm{c}}=\frac{K_{\mathrm{u}}}{3} \\
\tau_{\mathrm{I}}=\frac{P_{\mathrm{u}}}{0.5} .
\end{gathered}
$$

This gives $K_{\mathrm{c}}=5.68$ and $\tau_{1}=8.0$. Next, the $x_{\mathrm{B}}-V$ loop is under relay feedback test while the $T-T_{\mathrm{j}}$ loop is on automatic. The results are $K_{\mathrm{c}}=-0.75$ and $\tau_{\mathrm{I}}=57.6$. The $x_{\mathrm{D}}-R$ loop is then tuned while the other two loops on automatic. The tuning parameters for the $x_{\mathrm{D}}-R$ loop are: $K_{\mathrm{c}}=0.31$ and $\tau_{1}=$ 76.7. Actually, the tuning process can be terminated at this point (over a $4 \mathrm{~h}$ period). Figure 10 shows that this procedure is repeated for another sequence to ensure that these parameters really converge. Table 4 gives the tuning constants for the conventional structure. Following the same procedure, the tuning constants for the Luyben structure can also be found sequentially as shown in Fig. 11. The dynamics of these two structures are quite the same (e.g., in terms of time required for autotuning or $\omega_{\mathrm{u}}$ 's shown in Table 4). The balanced structure shows a bit different characteristic (Fig. 12). The loop speed for $T-T_{1}$ and $x_{\mathrm{B}}-V$ loops are quite the same as two structures shown previously. However, the relay feedback test on the $x_{\mathrm{D}}-h_{\mathrm{R}}^{\text {sct }}$ (level set 

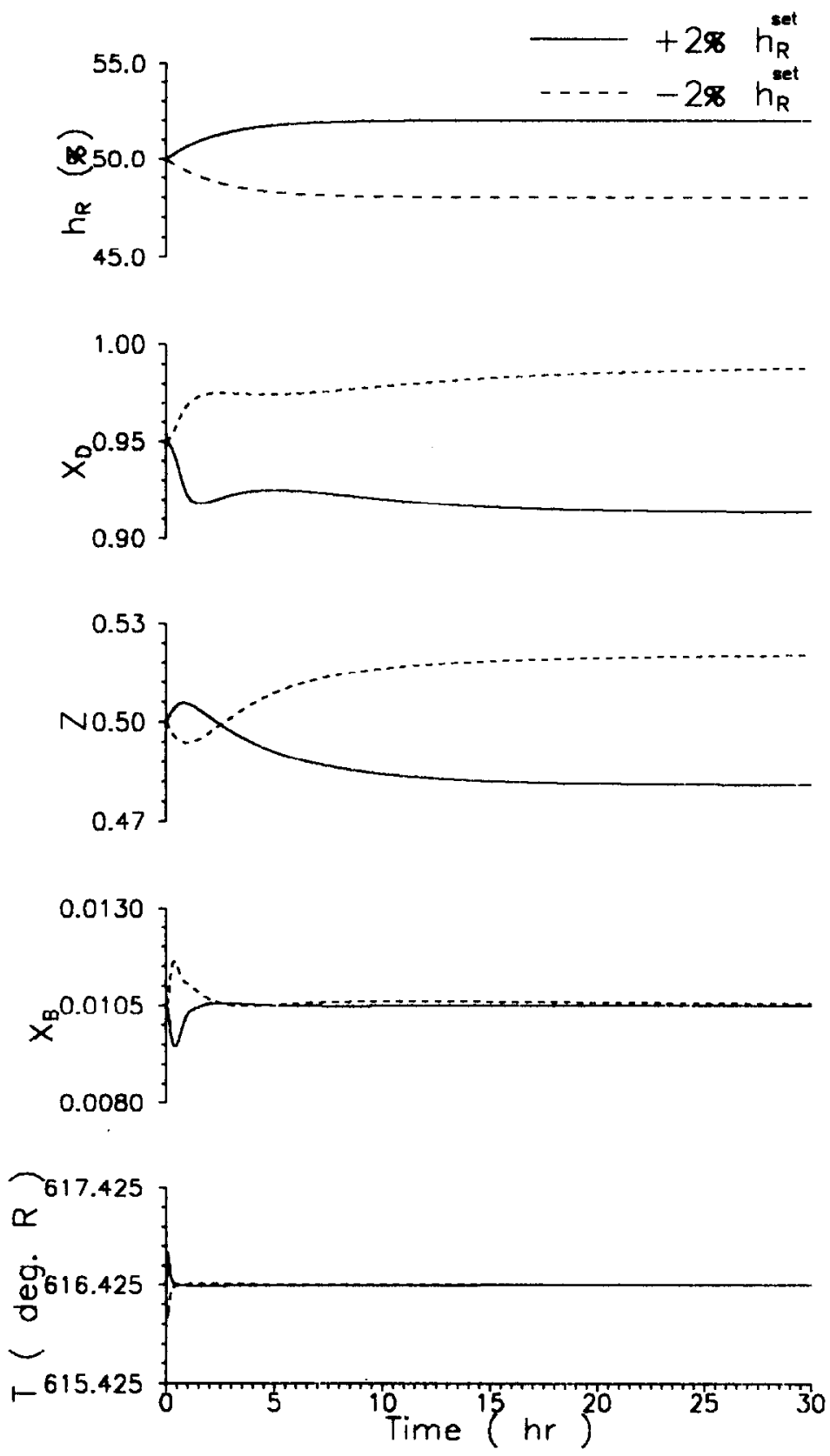

Fig. 9. Step responses of the proposed control structure for a step change in reactor level.

point) loop takes a much longer time. Despite the fact that the tuning constants converge in one sequence, it takes almost $7 \mathrm{~h}$ for one sequence. That implies that $x_{\mathrm{D}}-h_{\mathrm{R}}^{\text {set }}$ loop is much slower than the $x_{\mathrm{D}}$ loops for the other two structures $\left(x_{\mathrm{D}}-R\right.$ loop). Table 4 presents the tuning constants for all three control structures.

Actually, one can learn the dynamic characteristics of the plantwide system from relay feedback tests. For all these structures, the $T-T_{\mathrm{i}}$ loop is much faster than the other two composition loops (almost a order of magnitude faster) (Table 4). Therefore, the reactor temperature can be treated independently. The next faster loop is the $x_{B}-V$ loop as can be seen from the values of $\omega_{\mathrm{u}}$ (Table 4). For the conventional and Luyben structures, the loop speed for the two composition loops are quite the same and the difference (in the loop speed) becomes notable for the balanced scheme. The balanced control structure shows quite different loop speed and gives little dynamic interaction. This can be understood from the fact that the tuning 
constants from the first sequence and the second sequence are almost the same (Fig. 12).

The autotuning results clearly indicate that the plantwide control structure can be tuned effectively using the sequential tuning approach of Shen and Yu (1994).

\subsection{Closed-loop performance}

The three control structures are tested on the reactor/separator process by performing a series of non-linear dynamic simulations. Closed-loop performance as well as operability are employed to measure the effectiveness of these alternative control
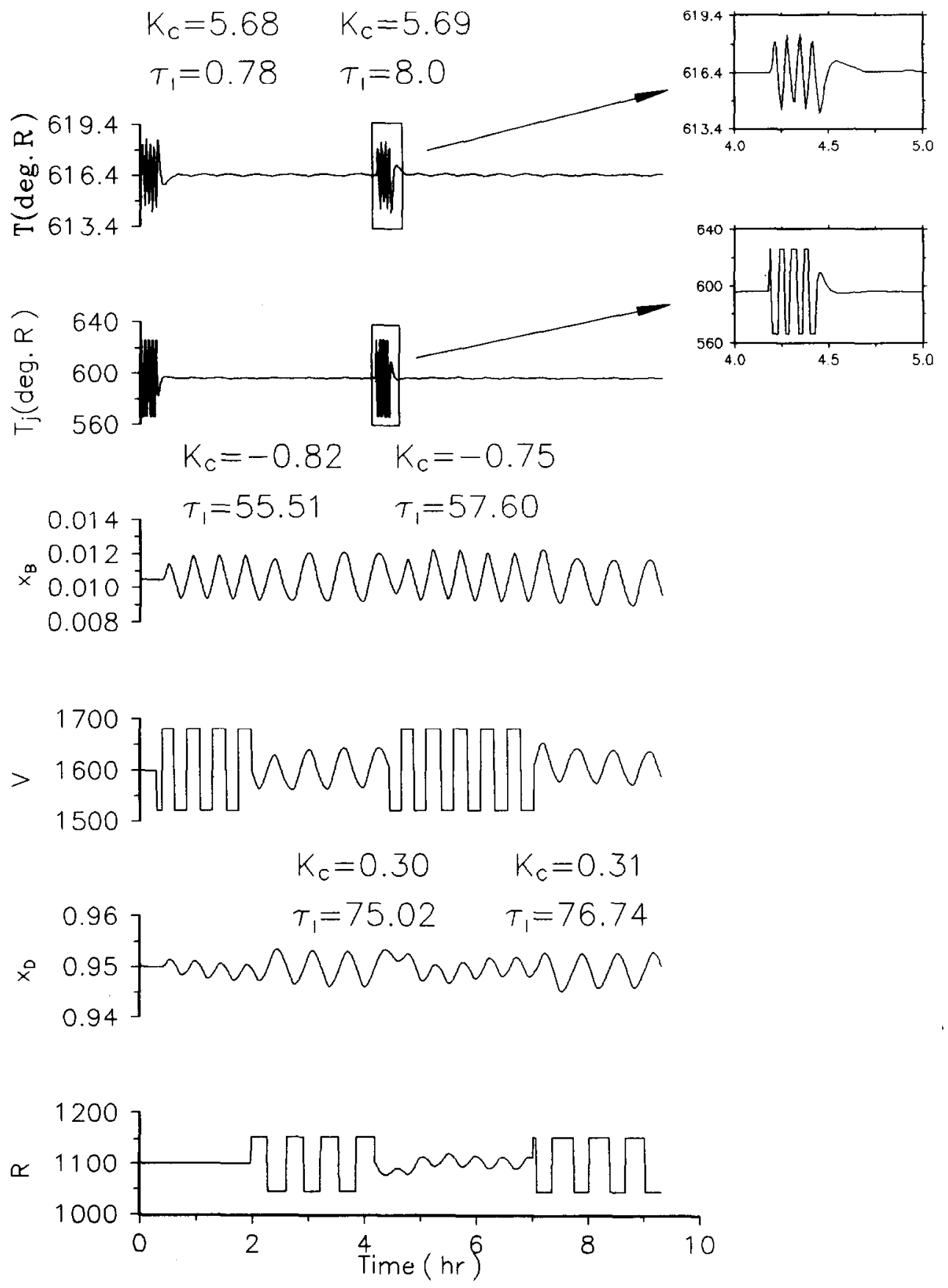

Fig. 10. Sequential tuning of the $T-T_{\mathrm{j}}, x_{\mathrm{B}}-V$ and $x_{\mathrm{D}}-R$ loops for the conventional structure. 


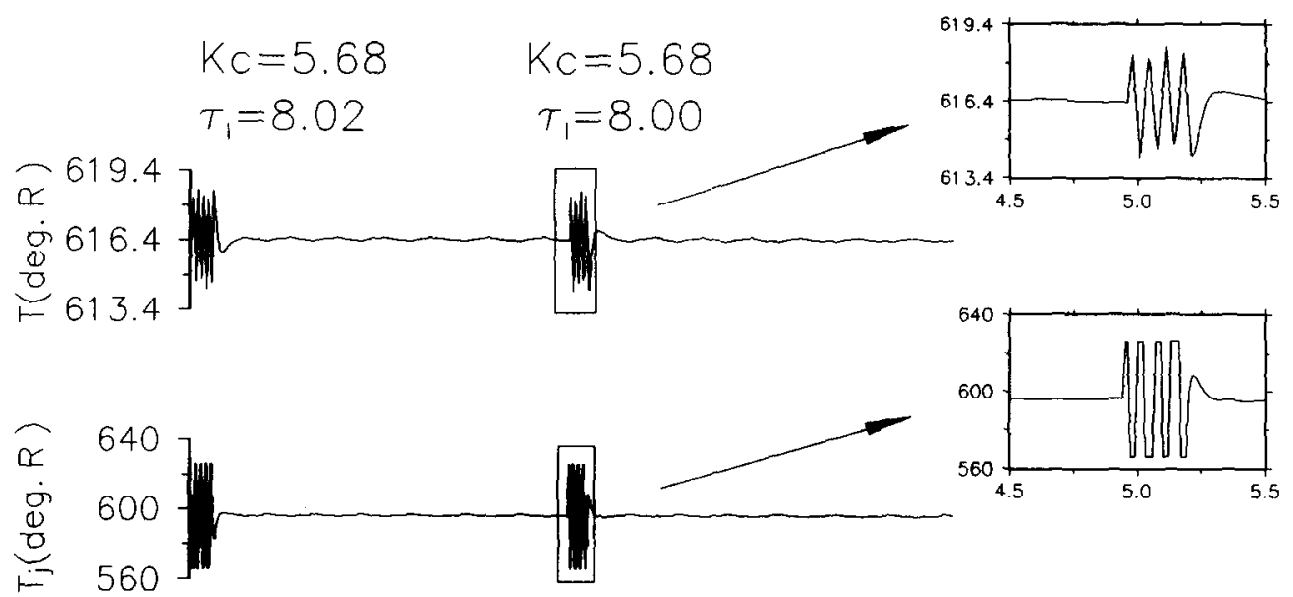

$$
K_{c}=-0.63 \quad K_{c}=-0.53
$$
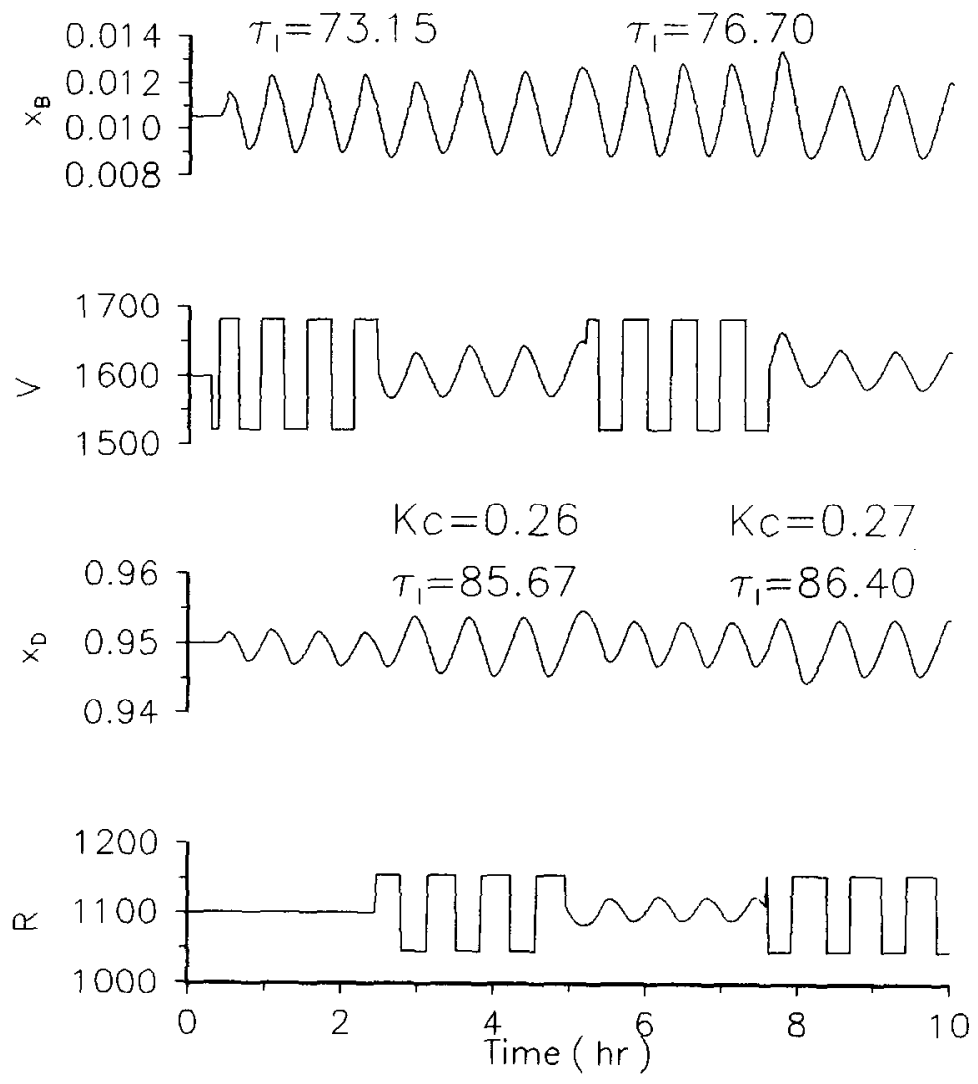

Fig. 11. Sequential tuning of the $T-T_{1}, x_{\mathrm{B}}-V$ and $x_{\mathrm{D}}-R$ loops for the Luyben structure.

structures. As far as the product quality is concerned, the response of $x_{B}$ is a more important indicator among these three controlled variables $\left(x_{\mathrm{B}}, x_{\mathrm{D}}\right.$ and $\left.T\right)$.

Figures 13-15 show what happens when step changes $( \pm 10 \%)$ are made in fresh feed flow rate for these three control structures. For the conventional structure, small changes in $F_{0}( \pm 10 \%)$ are amplified into very large deviations in the distillate flow rate $( \pm 30 \%)$ (Fig. 13). This is exactly the "snowball" effect pointed out by Luyben (1994). Despite the sensitivity problem is the recycle stream, the closedloop responses, e.g., for $x_{\mathrm{B}}$, is reasonable fast. That implies, at least, the tuning approach is satisfactory.

Figure 14 shows the closed-loop responses for Luyben structure for $\pm 10 \%$ fresh feed flow rate changes. Small changes in $F_{0}( \pm 10 \%)$ result in significant changes in the reactor level $( \pm 20.4 \%)$. It is also interesting to note that unlike the conventional structure the reactor brings the effluent composition 
(z) down to 0.452 for a $10 \% F_{0}$ increase. This is achieved at the expense of significant increase in the reactor holdup. Figure 14 also reveals that the fresh feed flow rate $\left(F_{0}\right)$ saturates momentarily when the throughput changes are made. However, the closedloop performance of $x_{\mathrm{B}}$ is much better than that of the conventional structure (Figs 13 and 14) despite the sensitivity problem in the reactor level. Figure 15 shows what happens when $\pm 10 \%$ step changes in the fresh feed flow rate are made for the balanced structure (structure $B_{2}$ ). The results show that the sensitivity problem in either recycle stream or reactor level, observed in the other two structures, no longer exists. The distillate flow rate and reactor level increase in proportion to the increase in the fresh feed flow rate. Figure 15 also confirms the finding that $x_{\mathrm{D}}-V_{\mathrm{R}}^{\text {set }}$ is the slowest loop in this system. The closed-loop performance of $x_{B}$ is similar
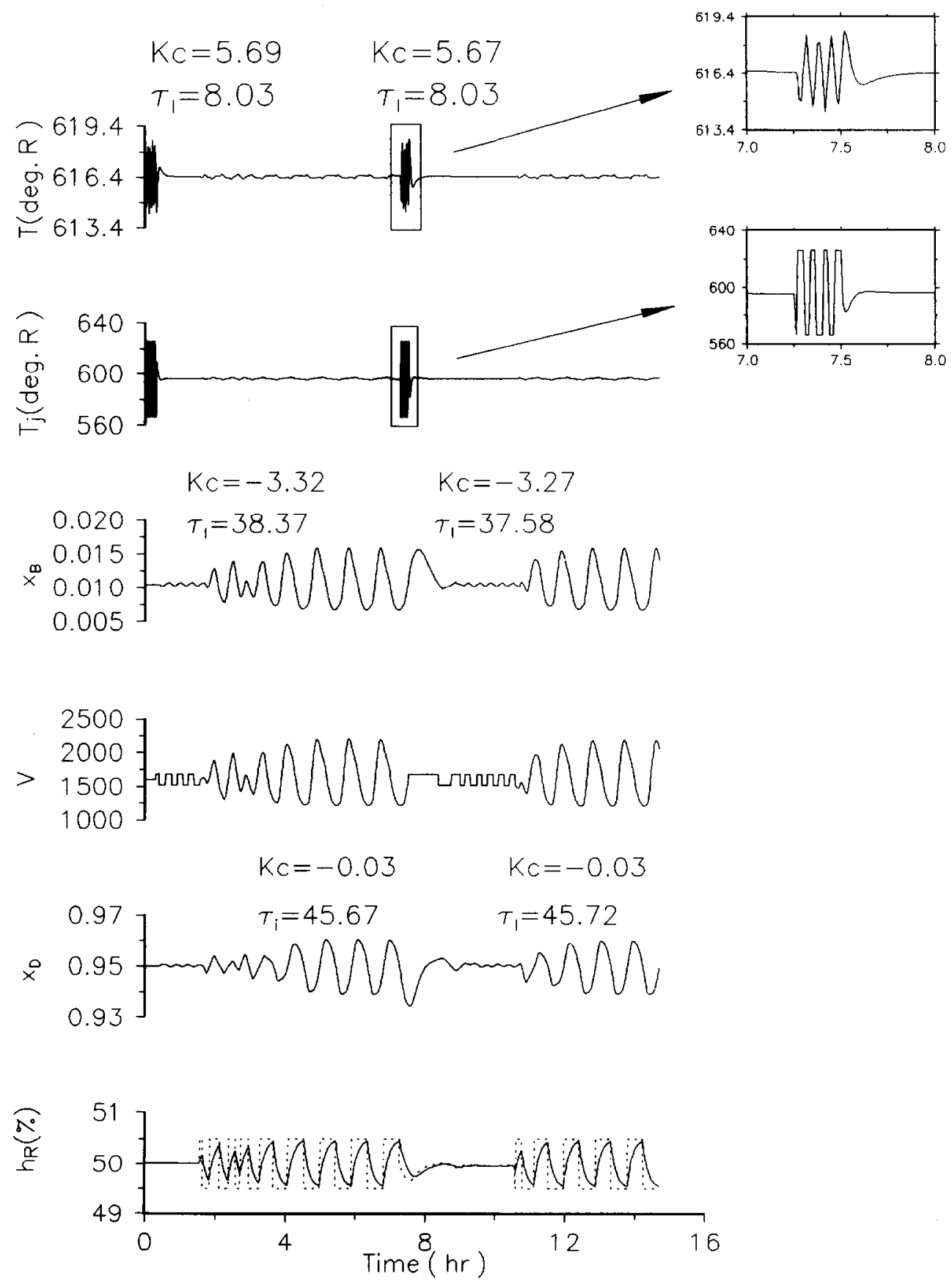

Fig. 12. Sequential tuning of the $T-T_{\mathrm{j}}, x_{\mathrm{B}}-V$ and $x_{\mathrm{D}}-h_{\mathrm{R}}^{\text {sct }}$ loops for the proposed structure. 

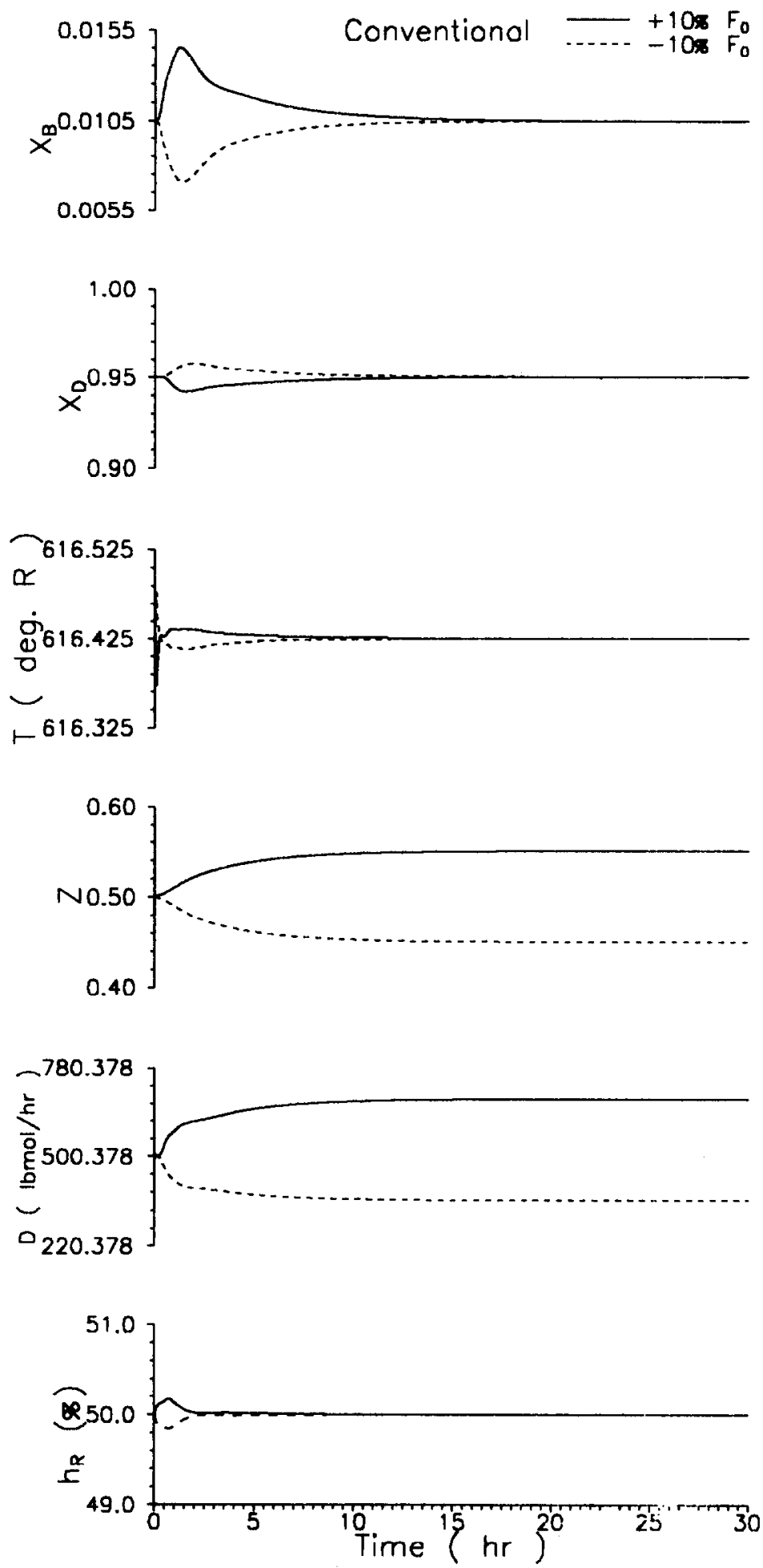

Fig. 13. Step responses of the conventional structure for $\pm 10 \% \quad F_{0}$ changes. 

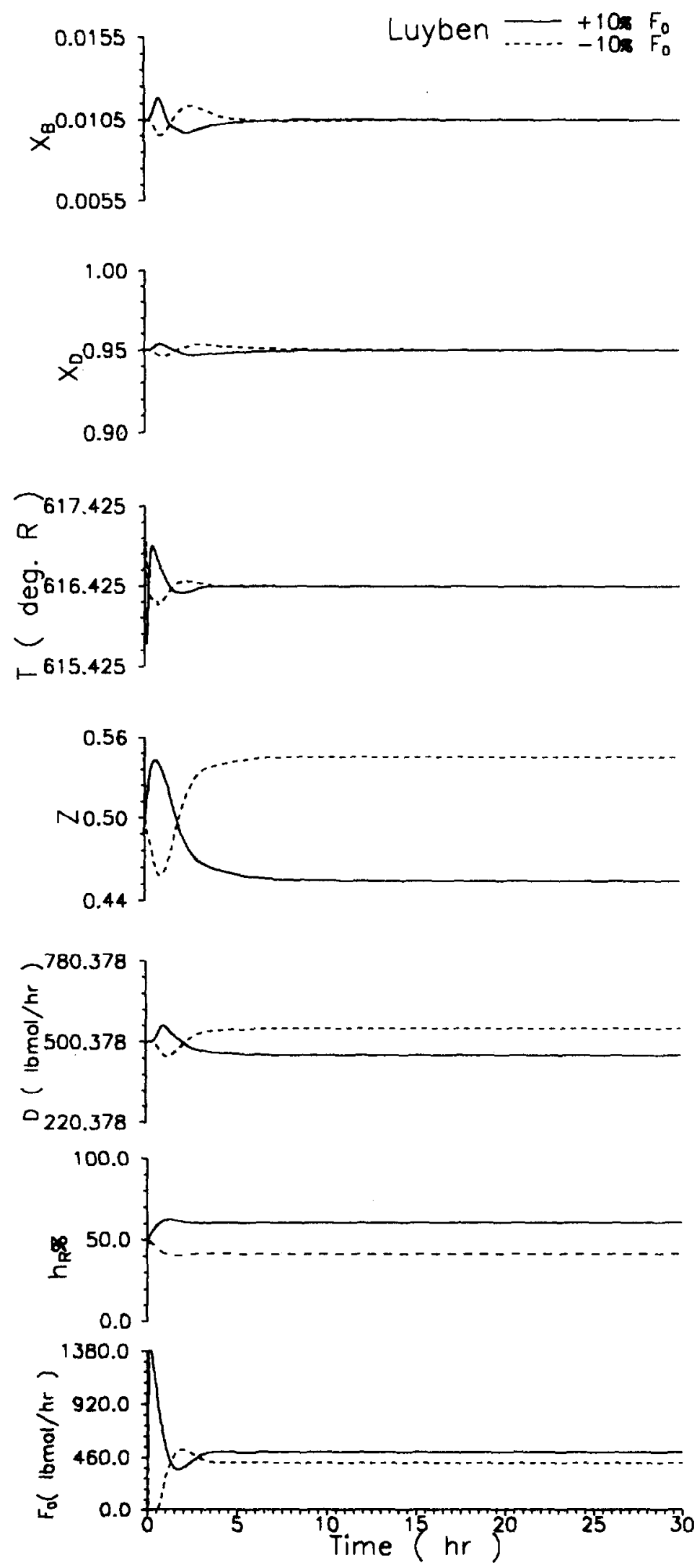

Fig. 14. Step responses of the Luyben structure $\pm 10 \% F_{0}$ changes. 

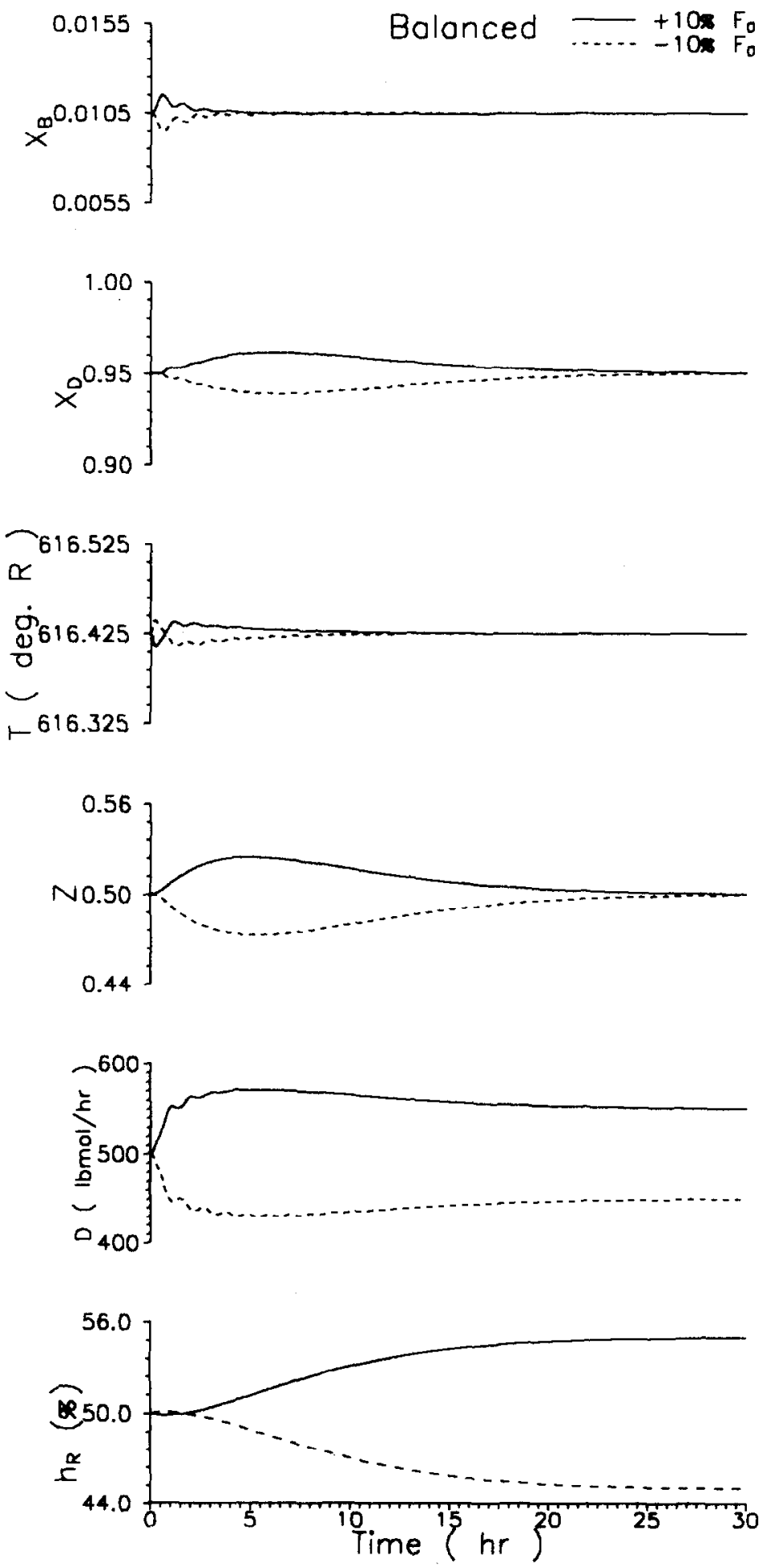

Fig. 15. Step responses of the balanced $\left(B_{2}\right)$ structure for $\pm 10 \% F_{0}$ changes. 

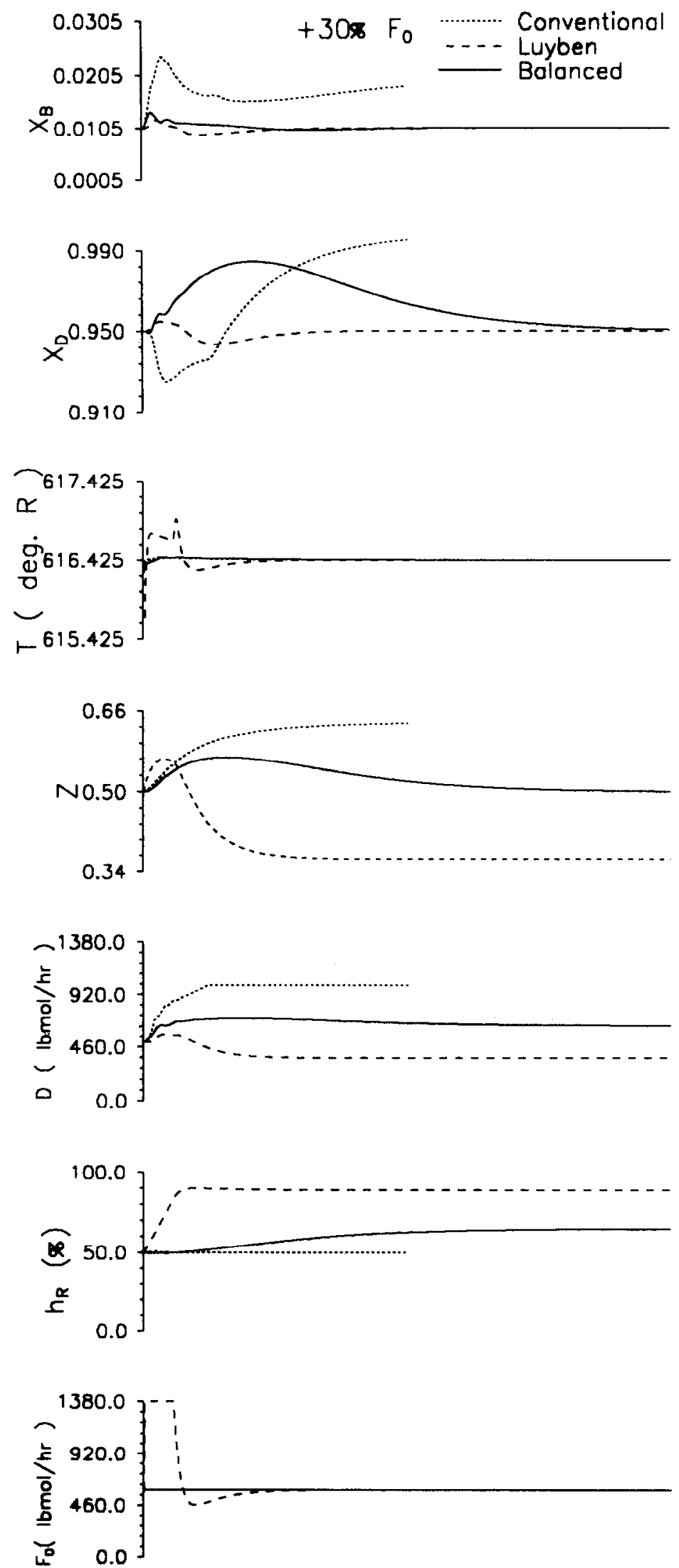

Fig. 16. Step responses of conventional, Luyben and balanced control structures for $+30 \% F_{0}$ change. 

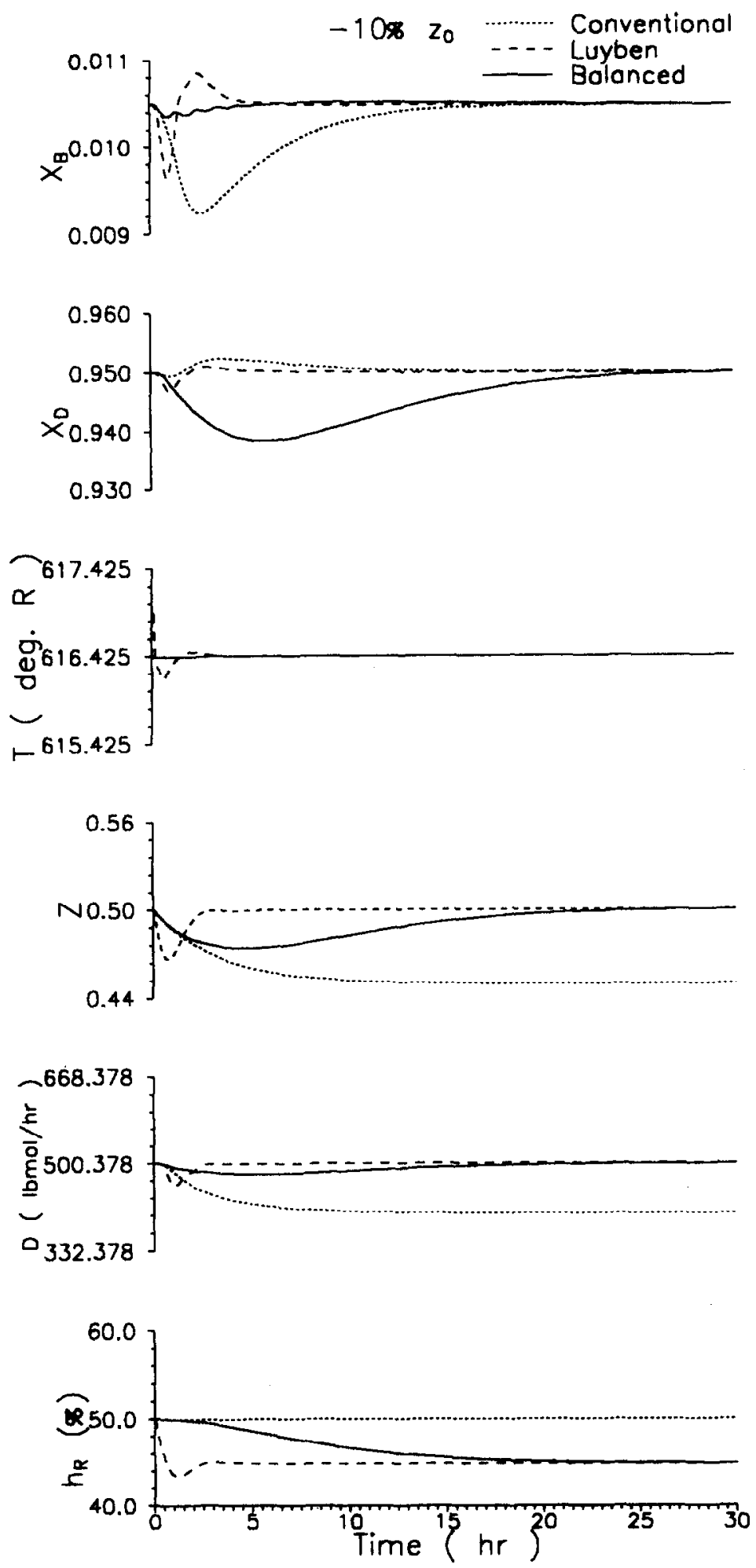

Fig. 17. Step responses of conventional, Luyben and balanced control structures for $-10 \% z_{0}$ change 
to that of Luyben structure. Despite the differences in sensitivity and performance of $x_{\mathrm{B}}$, the closed-loop responses are reasonable fast for all three structures.

A more realistic test for a throughput change, $30 \%$ increase in fresh feed flow rate, is used to evaluate these three control structures. Figure 16 shows the closed-loop responses for the conventional, Luyben and the balanced structures. For a $30 \%$ increase in $F_{0}$, the conventional structure fails to mect the product specifications $\left(x_{\mathrm{B}}\right)$ as the results of control valve saturation in the recycle stream (D in Fig. 16). For this throughput change, the reactor level almost overflows (levels off at $90 \%$ ). This occurs despite the fact that $x_{\mathrm{B}}$ is controlled reasonably well. Figure 16 shows that for the balanced structure good closed-loop performance is achieved without violating (or almost violating) process constraints.

Figure 17 shows what happens when the fresh feed composition decreases $10 \%$. Again better $x_{\mathrm{B}}$ responses can be achieved using the balanced structures. Despite the fact Luyben and the balanced structures show exactly the same steady-state behavior, the dynamic behavior differs between loops. The responses of $x_{\mathrm{D}}$ and $z$ are better controlled using Luyben structure. The conventional structure shows largest deviation in $x_{\mathrm{B}}$ while the reactor temperature and $x_{\mathrm{D}}$ are under relatively good control. In summary, the balanced control structure gives good closed-loop performance and, more importantly, can handle large load changes without violating process constraints.

\section{CONCLUSION}

The steady-state and dynamic behaviors of the reactor and separator in a recycle structure differ substantially from their individual unit counterparts. More importantly, limited throughput handling capability is observed when the control structure is not appropriately chosen. In this work, physical insights are given for the occurrence of the snowball effect which leads a limited disturbance rejection ability. Stcady-state analyses provide useful information to validate this potential problem in plantwide control and a new control structure, balanced scheme, is propsoed to overcome the snowball effect. The principle is simple: absorb the load changes evenly by all process units. Furthermore, a tuning procedure for plantwide control is also proposed. A rector/separator non-linear example is used to show the similarity and difference between control structures. Simulation results show that the balanced control structure is effective in handling large load changes while maintaining good closedloop performance.
Acknowledgement-This work is supported by the National Science Control of the R.O.C. under the grant NSC 84-2214-E-011-010.

\section{NOMENCLATURE}

$a=$ Amplitude of oscillation

$A=$ Reactant (light component)

$\mathbb{B}=$ Product (heavy component)

$B=$ Bottoms flow rate $(\mathrm{lbmol} / \mathrm{hr})$

$\mathrm{B}_{1}=$ Balanced control structure 1

$\mathrm{B}_{2}=$ Balanced control structure 2

$\mathrm{C}=$ Conventional control structure

$C_{\mathrm{p}}=$ Heat capacity $\left(\mathrm{Btu} / \mathrm{lb}_{\mathrm{m}}{ }^{\circ} \mathrm{R}\right)$

$D=$ Distillate flow rate $(\mathrm{lbmol} / \mathrm{hr})$

$E=$ Activation energy $(\mathrm{Btu} / \mathrm{lb} \mathrm{mol})$

$F=$ Reactor effluent flow rate $(\mathrm{lb} \mathrm{mol} / \mathrm{hr})$

$F_{0}=$ Fresh feed flow rate $(\mathrm{lb} \mathrm{mol} / \mathrm{hr})$

$h=$ Hcight of relay

$h_{\mathrm{R}}=$ Reactor level $(\%)$

$k=$ Specific reaction rate $\left(\mathrm{hr}^{-1}\right)$

$K_{\mathrm{c}}=$ Controller gain

$K_{\mathrm{u}}=$ Ultimate gain

$\mathrm{L}=$ Luyben's control structure

$P_{\mathrm{u}}=$ Ultimate period (min)

$R=$ Reflux flow rate (lb mol/hr)

$T=$ Reactor temperature $\left({ }^{\circ} \mathrm{R}\right)$

$T_{0}=$ Fresh feed temperature $\left({ }^{\circ} \mathrm{R}\right)$

$T_{\mathrm{D}}=$ Temperature of recycle flow rate $\left({ }^{\circ} \mathrm{R}\right)$

$T_{\mathrm{j}}=$ Reactor jacket temperature $\left({ }^{\circ} \mathrm{R}\right)$

$U=$ Overall heat-transfer coefficient $\left(\mathrm{Btu} / \mathrm{hrft}{ }^{\circ} \mathrm{R}\right)$

$V=$ Vapor boil-up flow rate (lb $\mathrm{mol} / \mathrm{hr}$ )

$V_{\mathrm{R}}=$ Reactor holdup (lb mol)

$W_{\min }=$ Minimum work for separation

$x_{\mathrm{B}}=$ Distillation bottoms composition (mole fraction)

$x_{\mathrm{D}}=$ Recycle flow composition (mole fraction)

$z=$ Reactor composition (mole fraction)

$z_{0}=$ Fresh feed composition (mole fraction)

Greek symbols

$\xi=$ Reaction conversion

$\zeta=$ Damping coefficient

$\omega_{\mathrm{u}}=$ Ultimate frequency $(\mathrm{rad} / \mathrm{min})$

$\tau_{\mathrm{I}}=$ Reset time

Superscripts

$-=$ Nominal value

set $=$ Set point

Subscripts

$\mathrm{D}=$ Control scheme with $\mathrm{D}$ fixed

$F=$ Control scheme with $F$ fixed

$\max =$ Upper bond of rangeability

$\min =$ Lower bound of rangeability

$\mathbf{R}=$ Control scheme with $\mathbf{R}$ fixed

$\mathrm{RR}=$ Control scheme with RR fixed

\section{REFERENCES}

Bristol E. H., On a new measure of interaction of multivariable process control. IEEE Trans. Autom. Cont AC-11, 133-134 (1966).

Buckley P. S. Techniques of Process Control. Wiley, New York (1964).

Buckley P. S., W. L. Luyben and J. P. Shunta, Design of Distillation Column Control Systems. Instrument Society of America, Research Triangle Park, NC (1985).

Cheung T. F. and W. L. Luyben, Liquid-level control in single tanks and casecade of tanks with proportionalonly and proportional-integral feedback controllers. Ind. Engng Chem. Fundam. 18, 15-21 (1979). 
Denn M. M. and R. Lavie, Dynamics of plants with recycle. Chem. Engng J. 24, 55-59 (1982).

Downs J. J, and E. F. Vogel, A plant-wide industrial process control problem. Computers Chem. Engng 17, 245-255 (1993).

Gilliland E. R., L. A. Gould and T. J. Boyle, Proc. Joint Automtic Control Conference, pp. 140-146 (1964).

Henley E. J. and J. D. Seader, Equilibrium-StageSeparation Operations in Chemical Engineering. Wiley, New York (1981).

Lee W. and V. W. Weekman, Advanced control practice in the chemical process industry: a view from industry. AIChE J. 22, 27-38 (1976).

Luyben W. L., Steady-state energy conservation aspects of distillation column control system design. Ind. Engng Chem. Fundam. 14, 321-325 (1975).

Luyben W. L., Process Modeling, Simulation and Control for Chemical Engineers, 2nd Ed. McGraw-Hill, New York (1990)

Luyben W. L., Practical Distillation Control. Van Nostrand Reinhold, New York (1992).

Luyben W. L., Dynamics and control of recycle systems. 1. Simple open-loop and closed-loop systems. Ind. Engng Chem. Res. 32, 466-475 (1993a).

Luyben W. L., Dynamics and control of recycle systems. 2 . comparison of alternative process designs. Ind. Engng Chem. Res. 32, 476-486 (1993b).

Luyben W. L., Dynamics and control of recycle systems. 3. Alternative process designs in a ternary system. Ind. Engng Chem. Res. 32, 1142-1153 (1993c).

Luyben W. L., Snowball effects in reactor/separator processes with recycle. Ind. Engng Chem. Res. 33, 299-305 (1994).

Luyben M. L. and C. A. Floudas, Analyzing the interaction of design and control-2. Reactor separator-recycle system. Computers chem. Engng 18, 971-994 (1994).

Marino-Galarraga M., T. J. McAvoy and T. E. Marlin, Short-cut operability analysis. 2. Estimation of $f_{i}$ detuning parameter for classical control systems. Ind. Engng Chem. Res. 26, 511-521 (1987)

McAvoy T. J. Interaction Analysis. ISA, Research Triangle Park, NC (1983).

McAvoy T. J. and N. Ye, Base control for the Tennessee Eastman problem. Computers chem. Engng 18, 383-413 (1994).

Morari M. and E. Zafiriou, Robust Process Control. Prentice-Hall, Englewood Cliffs, NJ (1990).

Papadourakis A, M. F. Doherty and J. M. Douglas, Relative gain array for units in plants with recycle. Ind Eng. Chem. Res. 26, 1259-1262 (1987).

Perlmutter D. D., Stability of Chemical Reactors. Wiley, New York (1965).

Price R. M. and C. Georgakis, Plantwide regulatory control design procedure using a tiered framework. Ind. Engng Chem. Res. 32, 2693-2705 (1993).

Price R. M., P. R. Lyman and C. Georgakis, Throughput manipulation in plantwide control structures. Ind. Engng Chem. Res. 33, 1197-1207 (1994).

Ray W. H., Multivariable process control-a survey. Computers chem. Engng 7, 367-394 (1983).

Shen S. H. and C. C. Yu, Use of relay-feedback test for automatic tuning of multivariable systems. AIChE J.40, 627-645 (1994).

Shinsky F. G., Distillation Control, 2nd Ed. McGraw-Hill, New York (1984)

Taiwo $O$., The design of robust control systems for plants with recycle. Int. J. Contr. 43, 671-678 (1986).

Tyreus B. D. and W. L. Luyben, Dynamics and control of recycle systems. 4. Ternary systems with one or two recycle streams. Ind. Engng Chem. Res. 32, 1154-1162 (1993).
Verykios X. and W. L. Luyben, Steady state sensitivity and dynamics of a reactor/distillation column systems with recycle. ISA Trans. 17, 31-41 (1978).

Yu C. C. and M. K. H. Fan, Decentralized integral controllability and D-stability. Chem. Engng Sci. 45, 3299-3309 (1990)

\section{APPENDIX}

The relationship between some important process variables $\left(F, D, z, V_{\mathrm{R}}\right)$ and fresh feed composition can be derived from equation (1)-(4). The expressions for three control structures (conventional, Luyben and proposed) are:

1. conventional structure (fixed $V_{\mathrm{R}}, x_{\mathrm{D}}, x_{\mathrm{B}}, k$ )

$$
\begin{gathered}
\left(\frac{F}{\bar{F}}\right)_{\mathrm{c}}=\frac{\left(\bar{x}_{\mathrm{D}}-\bar{z}\right)\left(\bar{z}_{0}-\bar{x}_{\mathrm{B}}\right)}{\bar{x}_{\mathrm{D}}\left(\bar{z}_{0}-\bar{x}_{\mathrm{B}}\right)-\bar{z}\left(z_{0}-\bar{x}_{\mathrm{B}}\right)} \\
\bar{D})_{\mathrm{c}}=\frac{\left(\bar{x}_{\mathrm{D}}-\bar{z}\right)}{\bar{x}_{\mathrm{D}}\left(\bar{z}_{0}-\bar{x}_{\mathrm{B}}\right)-\bar{z}\left(z_{0}-\bar{x}_{\mathrm{B}}\right)}\left(\frac{\bar{F}}{\bar{D}}\right)-\frac{\bar{F}_{0}}{\bar{D}} \\
\left(\frac{z}{\bar{z}}\right)_{\mathrm{c}}=\frac{\left(z_{0}-\bar{x}_{\mathrm{B}}\right)}{\left.\bar{z}_{0}-\bar{x}_{\mathrm{B}}\right)} \\
\left(\frac{V_{\mathrm{R}}}{\bar{V}_{\mathrm{R}}}\right)_{\mathrm{c}}=\frac{\left(\bar{x}_{\mathrm{D}}-\bar{z}\right)}{\bar{x}_{\mathrm{D}}\left(\bar{z}_{0}-\bar{x}_{\mathrm{B}}\right)-\bar{z}\left(z_{0}-\bar{x}_{\mathrm{B}}\right)}\left(\frac{\bar{F}}{\bar{D}}\right)-\left(\frac{\bar{F}_{0}}{D}\right) .
\end{gathered}
$$

2. Luyben structure (fixed $F, x_{\mathrm{D}}, x_{\mathrm{B}}, k$ )

$$
\begin{gathered}
\left(\frac{F}{\bar{F}}\right)_{\mathrm{L}}=1 \\
\left(\frac{D}{\bar{D}}\right)_{\mathrm{L}}=1 \\
\left(\frac{z}{\bar{z}}\right)_{\mathrm{L}}=1 \\
\left(\frac{V_{\mathrm{R}}}{\bar{V}_{\mathrm{R}}}\right)_{\mathrm{L}}=\frac{\left(z_{0}-\bar{x}_{\mathrm{B}}\right)}{\left(\bar{z}_{0}-\bar{x}_{\mathrm{B}}\right)} .
\end{gathered}
$$

3. Balanced structure (fixed $F / F_{0}, x_{\mathrm{B}}, z, k$ )

$$
\begin{gathered}
\left(\frac{F}{\bar{F}}\right)_{\mathrm{b}}=1 \\
\left(\frac{D}{\bar{D}}\right)_{\mathrm{b}}=1 \\
\left(\frac{z}{\bar{z}}\right)_{\mathrm{b}}=1 \\
\left(\frac{V_{\mathrm{R}}}{\bar{V}_{\mathrm{R}}}\right)_{\mathrm{b}}=\frac{\left(z_{0}-\bar{x}_{\mathrm{B}}\right)}{\left(\bar{z}_{0}-\bar{x}_{\mathrm{B}}\right)} .
\end{gathered}
$$

Notice that the results for the proposed structure is exactly the same as the Luyben structure despite the fact that specified variables are not the same. 